\title{
钯催化卤代烷烃参与的自由基型转化反应
}

\author{
周文俊 ${ }^{*, a, b}$ 张逸寒 ${ }^{b} \quad$ 曹光梅 ${ }^{b}$ 刘惠东 ${ }^{b}$ 余达刚*,b \\ $\left({ }^{a}\right.$ 内江师范学院化学化工学院 内江 641112) \\ ( ${ }^{b}$ 四川大学化学学院 绿色化学与技术教育部重点实验室 成都 610064)
}

\begin{abstract}
摘要 钯催化的交叉偶联反应经历了数十年的发展, 已经成为一种重要的有机合成手段. 相比于芳基和烯基卤代物, 烷基卤代物参与的偶联反应具有诸多挑战, 例如烷基卤代物和钯催化剂发生氧化加成较为困难, 之后形成的烷基钯物 种也面临易于发生 $\beta$ - $\mathrm{H}$ 消除和质子化等副反应的挑战. 近年来, 有机化学家们大力发展了涉及单电子转移的新型钯催 化体系, 实现了烷基卤代物参与的一系列自由基型偶联反应, 弥补了传统双电子转化模式的不足. 本文以参与反应的 底物类型为序, 综述了近年来钯催化卤代烷烃的自由基型转化反应新进展.
\end{abstract}

关键词＼cjkstart钯催化; 卤代烷烃; 自由基

\section{Palladium-Catalyzed Radical-Type Transformations of Alkyl Halides}

\author{
Zhou, Wen-Jun ${ }^{*, a, b} \quad{\text { Zhang, } \text { Yihan }^{b} \quad \text { Cao, Guangmei }}^{b} \quad$ Liu, Huidong ${ }^{b} \quad$ Yu, Da-Gang ${ }^{*, b}$ \\ ( ${ }^{a}$ College of Chemistry and Chemical Engineering, Neijiang Normal University, Neijiang 641112) \\ $\left({ }^{b}\right.$ Key Laboratory of Green Chemistry \& Technology of Ministry of Education, College of Chemistry, \\ Sichuan University, Chengdu 610064)
}

\begin{abstract}
Palladium-catalyzed cross-coupling reactions have been developed for decades as useful methods in organic synthesis. Compared to aryl and alkenyl halides, alkyl halides are more challenging to be applied in cross-coupling reactions. This mainly arises from the difficulty in oxidative addition of alkyl halides to palladium catalyst, sluggish reductive elimination and competitive side reactions, such as $\beta$-H elimination and protonation, of the resulting alkylpalladium intermediates. These challenges have partly been overcome with the significant development of novel palladium catalysis involving single election transfer. A variety of cross couplings of alkyl halides have been developed. In this review the recent palladium-catalyzed radical alkylation using alkyl halides with the order of different types of coupling partners is summarized.

Keywords palladium catalysis; alkyl halide; free radical
\end{abstract}

过渡金属催化的反应之中, 卤代烷烃参与的偶联反 应是一个具有挑战性的课题. 这是因为与芳基或烯基卤 代物相比，卤代烷烃参与的偶联反应具有众多的挑战: (1) $\mathrm{C}\left(\mathrm{sp}^{3}\right)-\mathrm{X}$ 比 $\mathrm{C}\left(\mathrm{sp}^{2}\right)-\mathrm{X}$ 键更富电子, 更难发生氧化 加成, 特别是二级、三级烷基卤代物; (2)发生氧化加成 后生成的烷基金属物种由于缺少 $\pi$ 电子对中心金属的稳 定作用, 反应活性更高, 很容易发生质子化或 $\beta$ - $\mathrm{H}$ 消除 等副反应; (3)涉及 $\mathrm{sp}^{3}$ 碳的还原消除困难, 难以得到预 期的目标产物. 由于卤代烷烃是重要的有机合成中间 体, 其种类繁多, 数量庞大, 结构多样, 化学家们一直 致力于该领域的研究. 自 Tamura, Suzuki 和 Knochel 等 ${ }^{[1]}$ 的开创性工作以来, 越来越多的体系被成功用于卤代烷
烃参与的偶联反应 ${ }^{[2]}$. 在这些体系中, 金属钯构建的体 系发挥着重要作用 ${ }^{[3]}$. 一般认为卤代烷烃参与的偶联反 应有两种启动模式: (1)双电子氧化加成. 在这种模式中, 烷基 $\mathrm{C}\left(\mathrm{sp}^{3}\right)-\mathrm{X}$ 键一般只能提供能量较高的 $\sigma^{*}$ 轨道(活 化的卤代烷烃除外)与低价钯物种作用，能垒较高，氧 化加成活性低, 由于空间位阻原因，二级、三级卤代烷 烃更难发生氧化加成. (2)单电子转移(SET). 单电子转 移过程也是卤代烷烃常见的催化循环启动模式. 在此模 式中, 低价钯物种首先与烷基 $\mathrm{C}\left(\mathrm{sp}^{3}\right)-\mathrm{X}$ 键发生单电子 转移, 形成卤素负离子的同时生成烷基自由基. 由于烷 基 $\mathrm{C}\left(\mathrm{sp}^{3}\right)$ 不直接与金属成键，这一过程相对比较容易. 近 年来, 越来越多的报道证明卤代烷烃参与的化学转化经

\footnotetext{
* Corresponding authors. E-mail: chemzhwj@126.com; dgyu@scu.edu.cn Received February 28, 2017; revised May 5, 2017; published online May 17, 2017.

Project supported by the National Program on Key Basic Research Project of China (973 Program, No. 2015CB856600).

国家重点基础研究发展计划(973 计划, No.2015CB856600)资助项目.
} 
历自由基历程, 通过该过程能够高效地构建碳碳键和碳 杂原子键. 本文按照反应底物的种类对近年来钯催化卤 代烷烃参与的自由基型化学转化进行综述, 主要包括与 烯烃、炔烃、芳烃、一氧化碳(CO)、腙以及胺等的反应.

\section{1 与烯烃的反应}

\section{1 分子间的 Heck 反应}

钯催化的 Heck 反应能够实现广谱性的烯烃与芳基 或烯基卤代物的偶联, 但将 Heck 反应拓展到简单烷基 卤代物具有一定的挑战. 早在 1986 年, Ishihara 课题组 ${ }^{[4]}$ 报道了钯催化的全氟碘代烷烃与碳碳不饱和键的烷基 化加成反应. 文中提到反应涉及自由基过程. 随后, Curran 课题组 ${ }^{[5]}$ 报道了零价钯促进的不饱和 $\alpha$-碘代羰基 化合物的环化反应，文中提出反应经历了 “原子转移 (Atom Transfer, AT)” 过程, 其中金属络合物起到引发自 由基链式反应的作用, 而非传统金属催化剂作用. 该反 应中 $\mathrm{Pd}\left(\mathrm{PPh}_{3}\right)_{4},\left(\mathrm{Bu}_{3} \mathrm{Sn}\right)_{2}$ 均可以有效促进反应的进行.

1992 年, 胡宏纹课题组 ${ }^{[6]}$ 报道了钯催化苄基卤代物 的烯基化反应(Eq. 1). 反应以 $\mathrm{Pd}(\mathrm{OAc})_{2}$ 为催化剂, 而三 苯基膦 $\left(\mathrm{PPh}_{3}\right)$ 以及联吡啶(bpy)等配体的加入会明显抑制 反应. 虽然该反应仅对带有吸电子基团的活化烯烃才具 有较高的反应活性, 但能够将烷基氯代物成功应用到 Heck 反应之中, 在 20 世纪 90 年代是非常重要的突破.
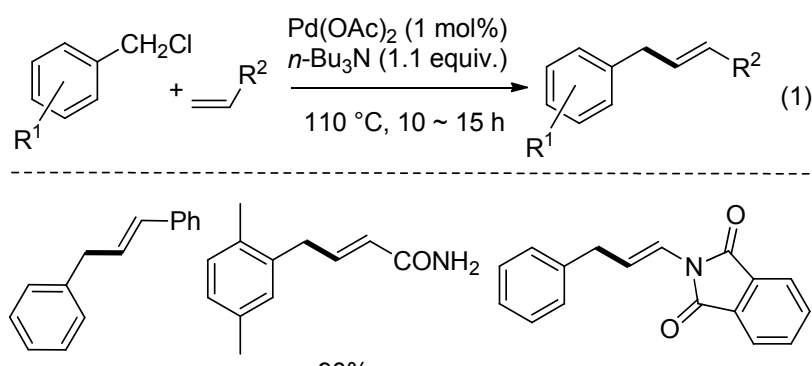

$57 \%$

$90 \%$

$65 \%$

Reutrakul 课题组 ${ }^{[7]}$ 于 2012 年报道了钯促进的(溴二 氟甲基)-磺酰基苯的 Heck 型反应(Scheme 1). 通过 $\operatorname{Pd}\left(\mathrm{PPh}_{3}\right)_{4}$ 催化, (溴二氟甲基) $)^{-}$磺酰基苯与苯乙烯类底物 或杂芳环化合物在 $100{ }^{\circ} \mathrm{C}$ 的甲苯溶剂中进行偶联, 高 效地实现 $\alpha$-烯基和杂芳环取代的苯磺酰二氟甲基化，所 得到的含 $\mathrm{PhSO}_{2} \mathrm{CF}_{2}$ 结构的产物也可转化为具有生物活 性的二氟甲基取代的烯烃.

2014 年, Zhou 课题组 ${ }^{[8]}$ 以 $\operatorname{Pd}(0)(\mathrm{dppf})$ 为催化剂, $\mathrm{Cy}_{2} \mathrm{NMe}$ 为碱, 在 $110{ }^{\circ} \mathrm{C}$ 的三氟甲苯中实现了非活化烷 基卤代物与简单烯烃的分子间 Heck 反应(Scheme 2). 经 过研究, 作者发现添加 LiI 可提高溴代物的转换产率. 对于大多数的一级烷基卤代物, $\mathrm{Pd}(\mathrm{dba})_{2}$ 搭配 $\mathrm{dppf}$ 能有 效抑制烷基卤代物消除等副反应的发生 ${ }^{[9]}$. 烷基氯代物
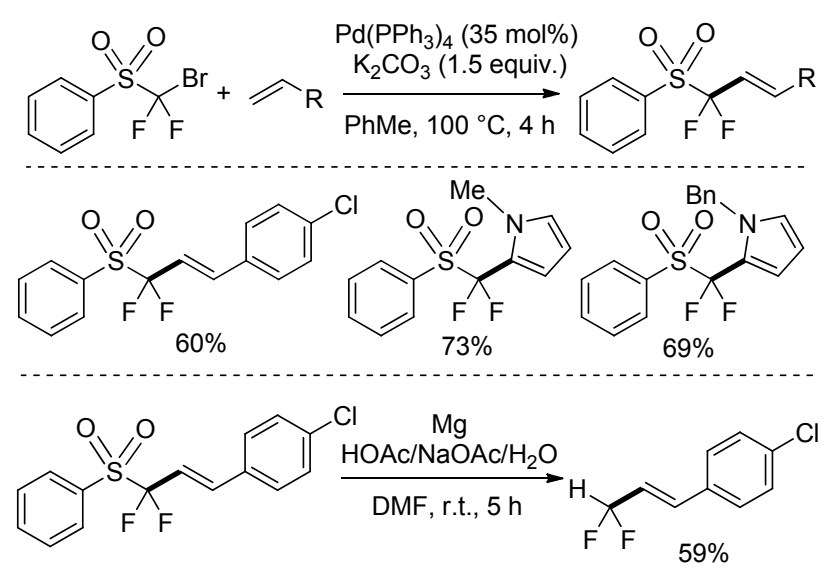

图式 1 钯促进的(溴二氟甲基)-磺酰基苯的 Heck 反应 Scheme 1 Palladium-promoted Heck-type reactions of [(bromodifluoromethyl)-sulfonyl]benzene

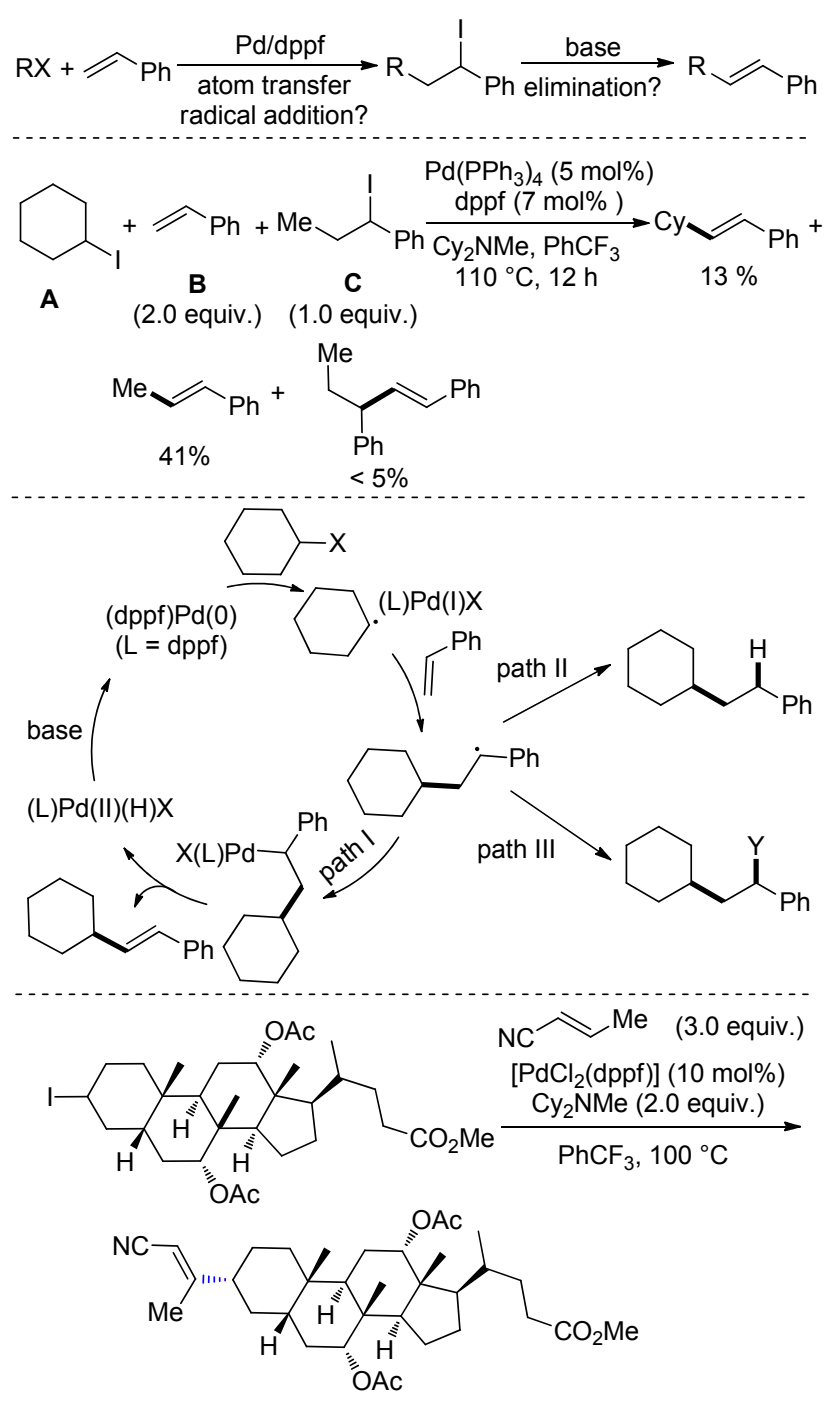

$68 \%$ yield, $d r=9: 1, E / Z=2: 1$

图式 2 钯催化非活化烷基碘代物的 Heck-型偶联反应 Scheme 2 Palladium-catalyzed Heck-type cross-couplings of unactivated alkyl iodides 
$(\mathrm{RCl})$ 也能很好地参与反应, 作者推断是 $\mathrm{RCl}$ 与 $\mathrm{LiI}$ 原 位生成的 RI 为活性的偶联试剂. 该反应具有较好的底 物兼容性, 容易衍生化, 而且能实现克级反应. 机理研 究中发现当疑似中间体 $\mathbf{C}$ 加到 CyI 与苯乙烯的 Heck 反 应中, C 被完全消耗, 但是只得到 $41 \%$ 的消除产物 (Scheme 2). 主要的副反应为苄基自由基的自偶联. 因 此, C 干涉了 CyI 参与的 Heck 反应, 使其产率从 $>70 \%$ 减少到 $13 \%$ (Scheme 2), 由此作者排除了原子转移自由 基加成形成苄基碘代物的可能(Scheme 2), 并提出了反 应可能的机理: (dppf)Pd(0)与烷基卤代物通过单电子转 移历程形成的烷基自由基, 进而与苯乙烯发生自由基加 成, 形成的茮基自由基物种和 $\operatorname{Pd}(\mathrm{I})$ 重组形成烷基钯物 种(dppf)XPd(II), 再经 $\beta$-H 消除得到产物(Scheme 2, path I).

通过反应条件控制, 由烷基自由基与烯烃加成形成 的自由基物种还可以实现别的转化, 如还原(Scheme 2, path II), 或者可以被别的基团捕获生成相应的产物 (Scheme 2, path III), 各种反应途径为实现该类反应的多 样性提供了可能.

几乎同时, Alexanian 课题组 ${ }^{[10]}$ 报道了类似的工作. 该反应以 $\mathrm{PdCl}_{2}$ (dppf)为催化剂, 以 $\mathrm{K}_{3} \mathrm{PO}_{4}$ 或 $\mathrm{Cy}_{2} \mathrm{NMe}$ 为 碱，在三氟甲苯中 $100{ }^{\circ} \mathrm{C}$ 的反应条件下，不同电性的烯 烃都可以参与反应，作者还将该反应应用到了天然产物 修饰上, 高立体选择性地得到相应的产物(Scheme 2).

\section{2 分子内的 Heck 反应}

一般而言, 分子内反应比分子间反应速度要快得 多，同时由于分子内反应在合成环状化合物方面的优势 而得到化学家们的青睐. 通过烷基卤代物参与的分子内 Heck 反应也能实现环状化合物的合成.

Alexanian 课题组 ${ }^{[11]}$ 于 2011 年报道了钯催化的烷基 碘代物参与的自由基型 5-exo 环化 Heck 反应(Scheme 3). 反应以 $\mathrm{Pd}\left(\mathrm{PPh}_{3}\right)_{4}$ 为催化剂, 1,2,2,6,6-五甲基哌啶(PMP) 为碱, 在 $110{ }^{\circ} \mathrm{C}, 1.01 \mathrm{MPaCO}$ 氛围下进行. 该反应底物 适用性较广, 以中等到较高产率得到 Heck 类型的五元 环产物. 作者发现, 对于一级烷烃碘代物若将反应中的 $\mathrm{CO}$ 氛围换成 $\mathrm{Ar}$ 氛围, 会有副产物产生. 对于二级碘代 物, $\mathrm{CO}$ 的影响则不显著. 尽管 $\mathrm{CO}$ 的作用还不是很清楚, 但作者推断在高压的 $\mathrm{CO}$ 中生成的 $\operatorname{Pd}\left(\mathrm{PPh}_{3}\right)_{x}(\mathrm{CO})_{y}$ 物种 是促进金属-自由基过程的活性物种 ${ }^{[12]}$.

2016 年, 刘会和刘青课题组 ${ }^{[13]}$ 通过巧妙的底物设 计, 利用芳基的位阻效应, 成功实现了第一例钯催化非 活化的烷基卤代物选择性的 6-endo 烷基化 Heck 反应 (Scheme 4). 该反应以 $\mathrm{PdCl}_{2}$ 作催化剂, $\mathrm{Cy}_{2} \mathrm{NMe}$ 作碱, 于 $110{ }^{\circ} \mathrm{C}$ 的甲苯溶液中高选择性地得到了 5-芳基-1,2,3,6四氢吡啶类衍生物. 反应底物适用范围广, 芳环上带有
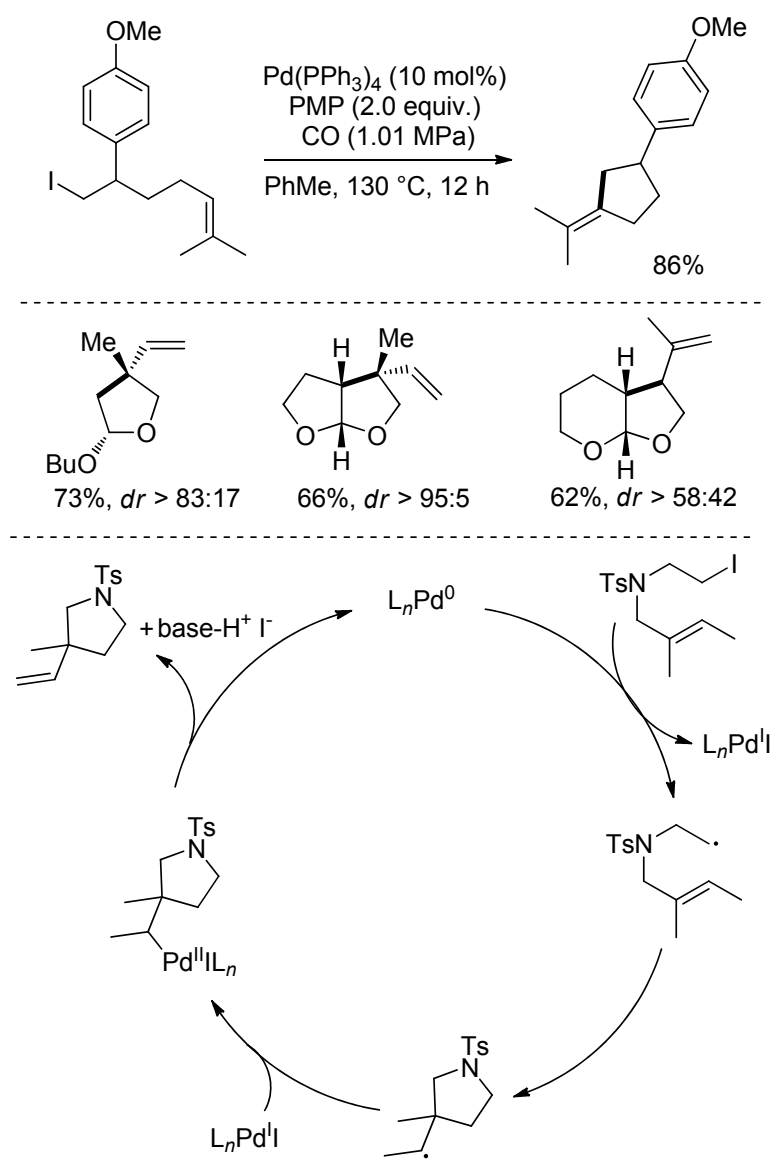

图式 3 钯催化的分子内环化反应

Scheme 3 Palladium-catalyzed 5-exo cyclization

给电子基或吸电子基官能团的底物都有着较高的收率.

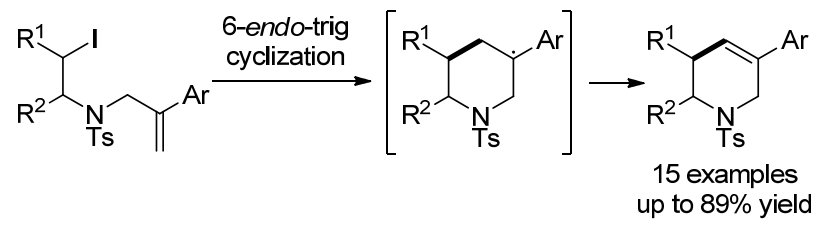

图式 4 钯催化的 6-endo 烷基化反应

Scheme 4 Palladium-catalyzed 6-endo cyclization

\section{3 还原 Heck 反应}

2016 年初, Ryu 课题组 ${ }^{[14]}$ 报道了在钯-光催化体系 下的活化烯烃的加氢烷基化的 Giese 型反应(Scheme 6). 该反应在氙灯保护箱中, 以 $\mathrm{PdCl}_{2}$ 作催化剂, $\mathrm{Et}_{3} \mathrm{~N}$ 作碱, Hantzsch 酯为氢源，在 $80{ }^{\circ} \mathrm{C}$ 苯中反应 $16 \mathrm{~h}$ 即可实现烯 烃的加氢烷基化. 该方法无需使用有毒的氢化锡, 在高 效反应的同时实现反应的绿色化. 另外, 该反应实现了 $\mathrm{C}\left(\mathrm{sp}^{3}\right)-\mathrm{I}$ 与 $\mathrm{C}\left(\mathrm{sp}^{2}\right)-\mathrm{X}(\mathrm{X}=\mathrm{Br}$ or $\mathrm{I})$ 之间的化学选择性, 为一锅法实现对两类 $\mathrm{C}-\mathrm{X}$ 键的分别官能团化提供了有 效途径. 作者提出了反应的可能机理: 首先在钯-光作 用下发生 SET 过程产生烷基自由基，进而与烯烃加成另 
一个烷基自由基，由于体系中没有强碱的存在，该自由 基不经 $\beta-\mathrm{H}$ 消除, 而是从 Hantzsch 酯的获得一个氢原子 得到还原的目标产物(Scheme 5).

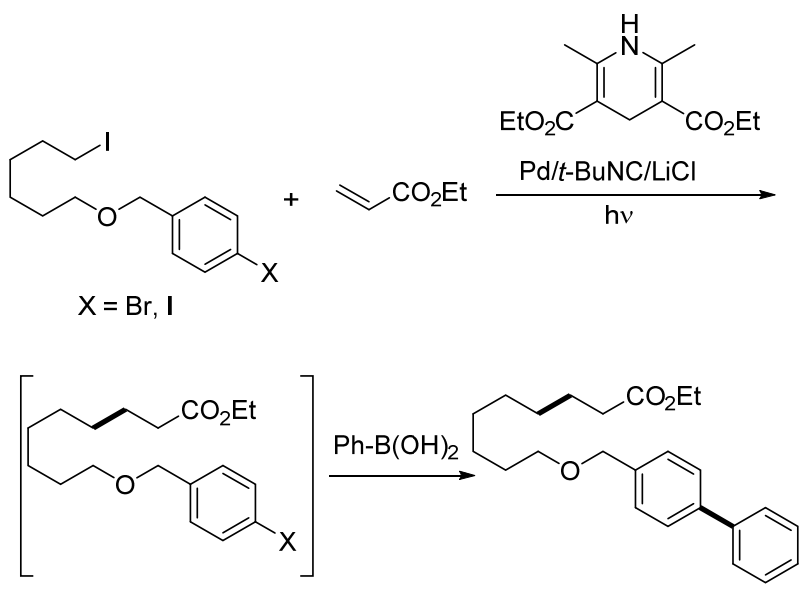

Proposed reaction mechanism

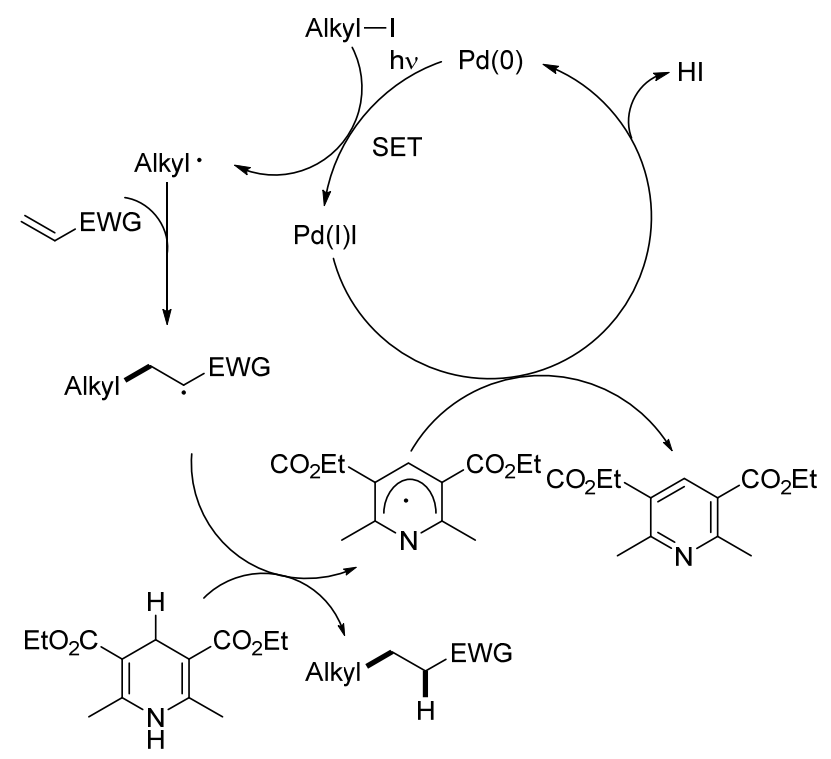

图式 5 钯/光体系下的烯烃加氢烷基化反应

Scheme 5 Hydroalkylation of alkenes under Pd/light system

\section{4 烯烃双官能团化反应}

除了以上转化之外, 烷基卤代物与烯烃加成形成的 烷基自由基中间体还可以参与其他化学键构建(如碳卤 键和碳碳键), 实现烯烃的双官能团化反应. 2012 年, 姜 雪峰课题组 ${ }^{[15]}$ 发展了 $\mathrm{Pd} / \mathrm{dppf}$ 催化非活化烷基碘代物参 与的原子转移自由基环化反应(atom transfer radical cyclization, ATRC) (Scheme 6). 该反应在 $130{ }^{\circ} \mathrm{C}$ 下反应 24 $\mathrm{h}$, 得到了一系列五元环化产物. 作者通过机理研究证 明该过程涉及烷基自由基过程, 并认为在该无碱体系 中, 烷基自由基和双键反应新形成的碳自由基很有可能 直接与 $\operatorname{Pd}(\mathrm{I}) \mathrm{I}$ 发生原子转移实现碳碘键的构建.
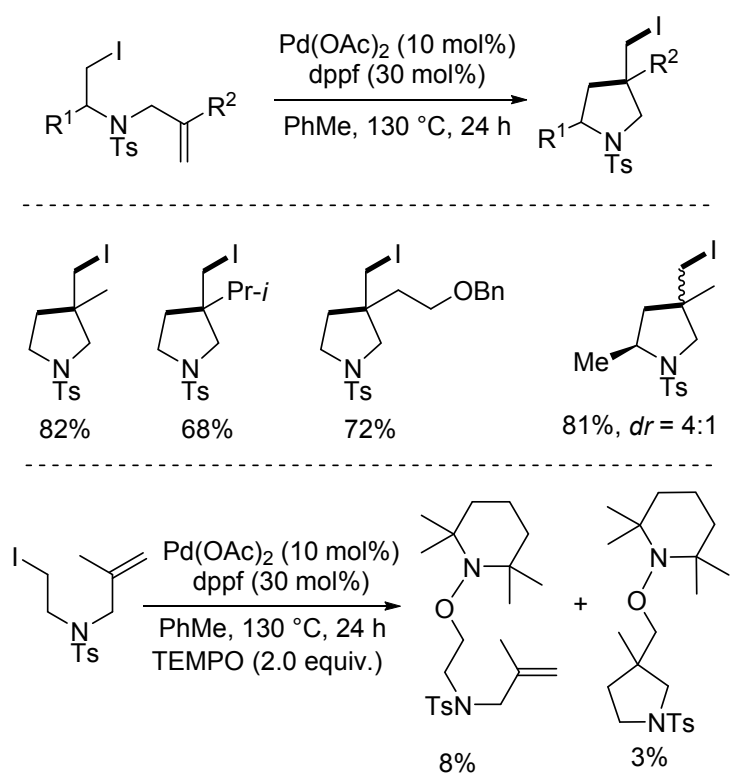

图式 6 钯催化烷基碘代物的原子转移自由基环化反应 Scheme 6 Palladium-catalyzed atom transfer radical cyclization of alkyl iodide

2014 年, 李金恒课题组 ${ }^{[16]}$ 报道了一种新型钯催化 的烯烃双官能团化反应 (Scheme 7). 该反应以 $\mathrm{PdCl}_{2}(\mathrm{MeCN})_{2}$ 作催化剂, dppe 作配体, $\mathrm{Ag}_{2} \mathrm{CO}_{3}$ 作氧化剂, 于 $100{ }^{\circ} \mathrm{C}$ 甲苯中反应 $12 \mathrm{~h}$ 得到了系列二氢吲哚-2-酮类 化合物. 此方法可应用于不同类型的 $N$-芳基烯烃以及 一级、二级、三级、 $\alpha$-羰基烷基溴代物. 作者提出了可 能的反应路径: 中间体 $\mathbf{A}$ 加成到烯烃碳碳双键上, 产生 自由基 $\mathbf{B}$, 接着 $\mathbf{B}$ 环化形成自由基中间体 $\mathbf{C}, \mathbf{C}$ 再被 $\operatorname{Pd}(\mathrm{II}) \mathrm{L}_{n}$ 物种氧化得到阳离子中间体 $\mathbf{D}$, 最后经脱质子 化形成产物. 此外不能排除 $\mathrm{Pd}(\mathrm{II}) / \mathrm{Pd}(0)$ 的催化历程.

2015 年, 童晓峰课题组 ${ }^{[17]}$ 报道了钯催化 $N$-烯丙基$\alpha$-氯代物的原子转移自由基环化反应(Eq. 2), 高选择性 地合成了一系列 $\gamma$-内酰胺衍生物. 该反应利用 $\operatorname{Pd}(\mathrm{cod})-$ $\mathrm{Cl}_{2}$ 作为催化剂前体, IMes 为配体, $\mathrm{NaI}$ 为碘源, 在 $135{ }^{\circ} \mathrm{C}$ 的邻二甲苯中下高效地实现了 $N$-烯丙基- $\alpha$-氯代 物的环化反应.

2016 年初, 段新华课题组 ${ }^{[18]}$ 实现了钯催化非活化 烷基卤代物与丙烯酰胺与的串联反应(Eq. 3). 反应以 $\mathrm{PdCl}_{2}$ 作催化剂, $\mathrm{dppf}$ 为配体, $\mathrm{K}_{3} \mathrm{PO}_{4} \cdot 3 \mathrm{H}_{2} \mathrm{O}$ 为碱, 在 $100{ }^{\circ} \mathrm{C}$ 的二乙二醇二甲醚中, 芳基丙烯酰胺能顺利地与 烷基卤化物发生反应，高效地实现二氢吲哚-2-酮类化 合物的合成. 该反应无需加入氧化剂, 底物适应性广, 官能团兼容性好. 值得注意的是, 当使用二级卤代烷烃 进行环化反应时, 必须在反应中添加 NaI 才能得到相应 产物. 作者推断, 较为活泼的二级溴代烷烃在反应中可 能涉及了一个溴碘交换的过程. 2,2,6,6-四甲基哌啶氧化 

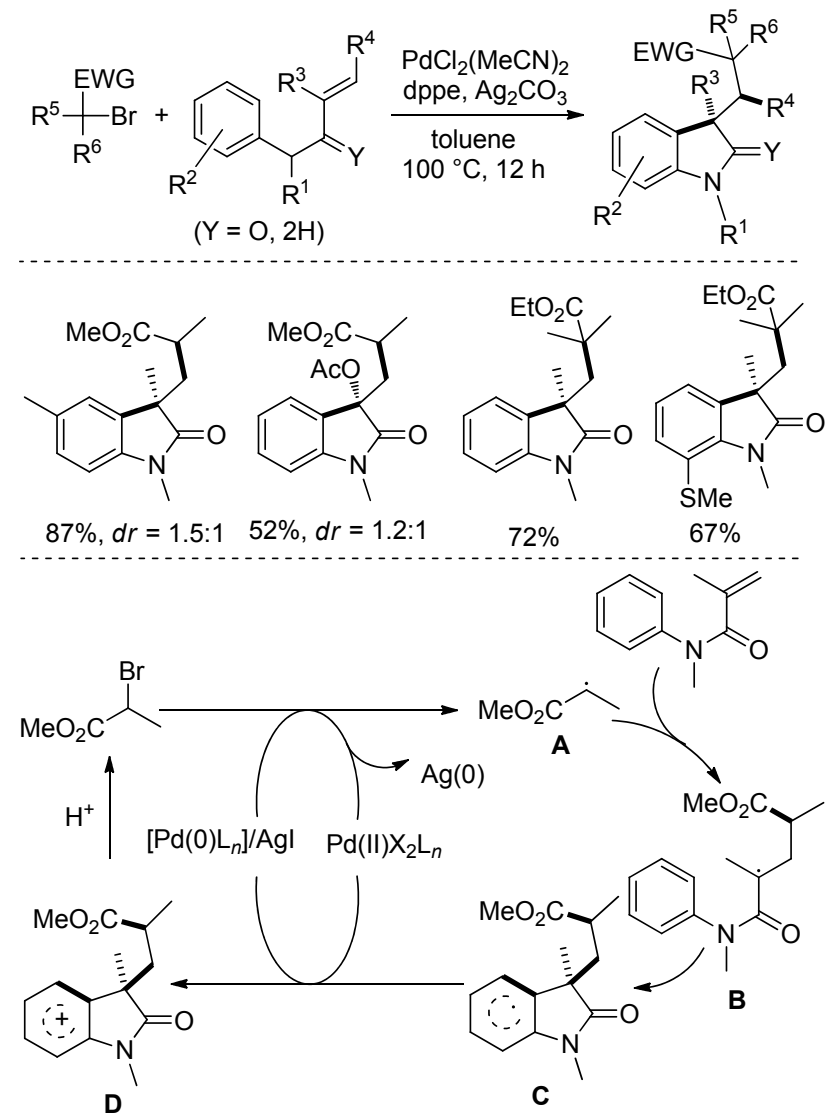

图式 7 自由基型烯烃双官能团化反应

Scheme 7 Radical alkene difunctionalizations
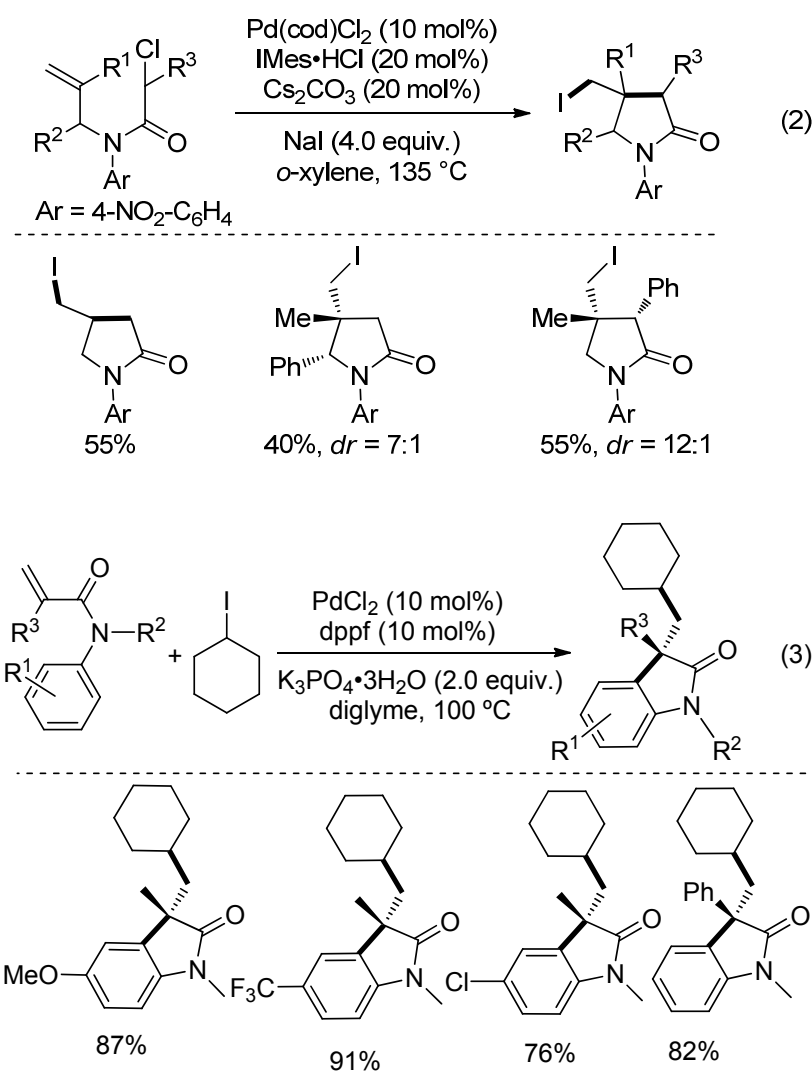

物(TEMPO)和 2,6-二叔丁基-4-甲基苯酚(BHT)抑制实验 表明该反应可能涉及自由基过程. 此外, 动力学同位素 效应 $(\mathrm{KIE})$ 实验结果表明碳氢键的活化不是反应的决速 步，由此作者认为反应经历了一个自由基过程.

作为药物分子中常见的结构, 含氟官能团的引入方 法一向引人注目. 二氟烷基溴代物作为一种常见的二氟 甲基化试剂, 被广泛应用于自由基化学中 ${ }^{[16]} .2016$ 年, 夏晓峰课题组 ${ }^{[19]}$ 利用钯催化丙烯酰胺与二氟澳代乙酸 乙酯的自由基型二氟烷基化/环化反应(Eq. 4), 合成了一 类含氟的异喹啉二酮骨架分子. 全氟代烷基碘化合物也 能在该体系下进行反应.

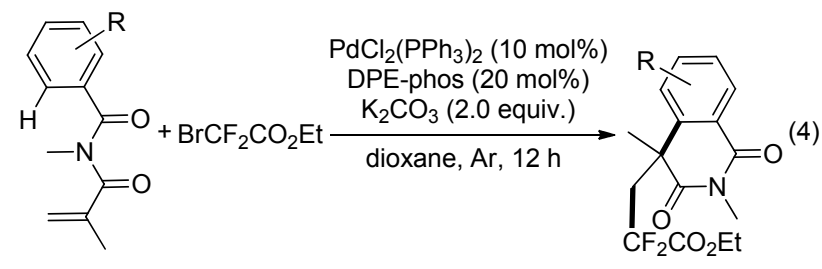<smiles>CCCC(F)(F)CCC1(C)c2cc(F)ccc2C(=O)N(C)C(=O)C1(C)CCCC(=O)OCC</smiles>

$75 \%$

$55 \%$

$50 \%$

\section{2 与炔烃的反应}

相对于烯烃而言，由于炔烃中 $\mathrm{sp}$ 碳原子的电负性 比烯烃 $\mathrm{sp}^{2}$ 碳原子的电负性强, 使得 $\pi$ 电子云不易极化, 因此自由基对炔烃亲电加成条件较为苛刻. 1986 年, Ishihara 课题组 ${ }^{[4]}$ 曾报道, 在 $\mathrm{Pd}\left(\mathrm{PPh}_{3}\right)_{4}$ 为催化剂, 正己烷 为溶剂, 炔可以与全氟烷基碘代物在 $60 \sim 67{ }^{\circ} \mathrm{C}$ 反应生 成烯基碘代物. 通过 1,4-二硝基苯作为自由基抑制剂的 实验证明该反应可能涉及自由基机理.

2013 年, Cook 课题组 ${ }^{[20]}$ 报道钯催化下炔与非活化 的烷基碘代物的插入、还原反应(Scheme 8), 以此来合 成一系列三取代的烯烃. 该反应具有反应条件温和、官 能团容忍性好等特点. 初步的机理探究过程中, 作者发 现底物为 2 -碘代乙基二苯乙炔, 其产物是以 $E / Z$ 比为 $1: 3$ 的异构体存在，作者推测该反应可能经历烯基钯 异构化过程, 但膦配体的位阻和电性对该反应 $E / Z$ 比值 没有明显影响. 随后作者推测该反应可能经历了烯基自 由基异构化过程，自由基控制实验中, TEMPO 抑制剂对 反应有一定的抑制作用, BHT 对产率没有影响等实验结 果. 综上，作者提出该反应可能经历一个杂化的有机钯 物种和烯基自由基过程. 


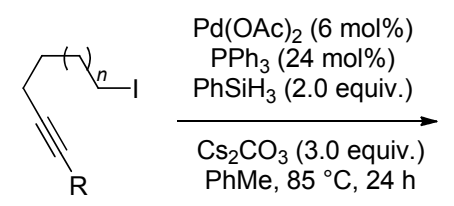

$n=1,2$

$\mathrm{R}=$ aryl, heterocycle, and alkyl

(1) vinyl palladium isomerization:
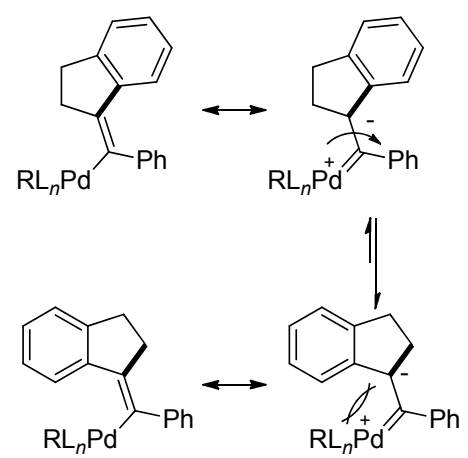

(2) vinyl radical isomerization:

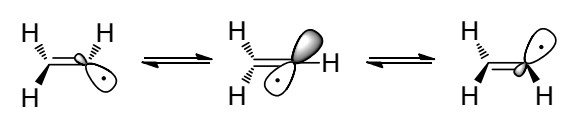

图式 8 钯催化下炔的插入/还原反应和可能的机理

Scheme 8 Palladium-catalyzed alkyne insertion/reduction reactions and proposed mechanism

随后，该课题组 ${ }^{[21]}$ 报道了 $\beta$-H 存在下钯催化分子内 碘原子迁移反应(Scheme 9). 该反应以 $\mathrm{Pd}\left(\mathrm{PPh}_{3}\right)_{4}$ 为催化 剂, $\mathrm{Cs}_{2} \mathrm{CO}_{3}$ 为碱, 甲苯为溶剂, $50{ }^{\circ} \mathrm{C}$ 条件下, 一系列非 环状的二级烷基碘代物能以较高的收率转变为含碘甲 基的二奎烷类化合物. 反应具有原子经济性高、官能团 兼容性好、产物易于衍生化等特点. 作者提出的可能反 应机理为: 碘代物在零价钯作用下生成烷基自由基, 同 时产生的 $\operatorname{Pd}(\mathrm{I})$ 与端烯发生配位作用, 随后与参键发生 分子内自由基加成反应得到烯基自由基, 再与 $\mathrm{Pd}(\mathrm{I})$-烯 烃络合物反应得到目标产物.

2015 年, Nevado 课题组 ${ }^{[22]}$ 报道了钯催化下端炔双 官能团化反应 (Scheme 10). 在 $\mathrm{PdCl}_{2}\left(\mathrm{PPh}_{3}\right)_{2}$ 催化下, $\mathrm{K}_{2} \mathrm{CO}_{3}$ 为碱, 二氯甲烷和水作为溶剂, 芳基或烯基硼酸 和全氟碘代物同时与端炔进行反应, 以较高区域选择性 及立体选择性合成系列三取代的烯烃化合物. 作者通过 控制实验提出可能的反应机理: 二价钯在嗍酸的作用下 原位生成零价钯, 进而与全氟碘代烷发生单电子转移形 成具有亲电性的全氟烷基自由基，该自由基与炔烃反应 形成烯基自由基, 再经过单电子转移(path I)或与硼酸的 转金属化(path II)形成烯基钯物种, 最后经过还原消除 得到目标产物.

与此同时, 梁永民课题组 ${ }^{[23]}$ 报道了类似的三组分 反应(Eq. 5). 在氩气氛围中, $80{ }^{\circ} \mathrm{C}$ 条件下, 以 $\mathrm{Pd}\left(\mathrm{PPh}_{3}\right)_{4}$ 为催化剂, 通过一锅法高效地实现烯基双官能团化产物
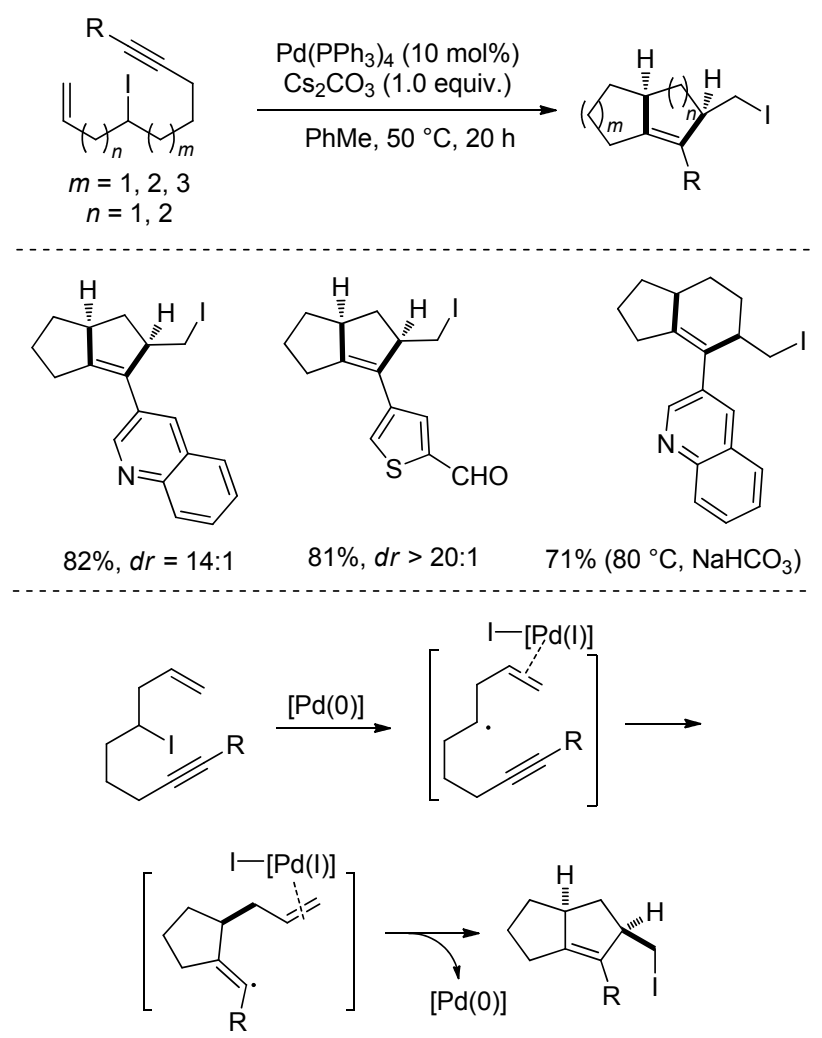

图式 $9 \beta-\mathrm{H}$ 存在下钯催化分子内碘原子迁移反应 Scheme 9 Palladium-catalyzed intramolecular iodine-transfer reactions in the presence of $\beta$-hydrogen atoms

的合成. 在该体系中烷基炔也能够参与反应，具有较广 的底物范围. 基于控制实验及已有的文献报道, 作者认 为该反应经历二氟烷基自由基加成机理，与上述报道 path II 相同.

2016 年, Chaładaj 课题组 ${ }^{[24]}$ 报道了一种钯络合物催 化下炔烃的烷基化反应(Scheme 11). 一系列炔烃(端位 和非端位)、芳基嗍酸、全氟碘代物通过一锅法反应，以 较高的收率、高区域选择性、高立体选择性得到三取代 或四取代的烯烃. 作者推测可能的反应机理包含两个独 立的催化循环, 分别是自由基型 $\operatorname{Pd}(0) / \operatorname{Pd}(\mathrm{I})$ 和典型的 Suzuki 偶联机理 $\operatorname{Pd}(0) / \mathrm{Pd}(\mathrm{II})$, 其间以零价钯和烯基碘代 物作为桥梁.

多组分反应是绿色化学的重点之一, 因为其较高的 原子经济性和步骤经济性而备受关注. 2016 年, 梁永民 课题组 ${ }^{[25]}$ 基于之前钯催化下端炔的芳基化和多氟烷基 化的研究, 发展了钯催化下端炔的二氟烷基化和羰基化 反应(四组分反应)(Eq. 6). 反应以 $\mathrm{PdCl}_{2}\left(\mathrm{PPh}_{3}\right)_{2}$ 为催化 剂, DPEphos 为配体, 碳酸钾为碱, 一系列端炔、二氟碘 代乙酸乙酯, 醇/胺与一氧化碳 $(101 \mathrm{kPa})$ 在一锅法条件 下, 高区域选择性地合成了 $\beta$-二氟烷基不饱和酯/酰胺. 通过系列控制实验，作者认为二氟烷基自由基的形成对 该反应至关重要. 

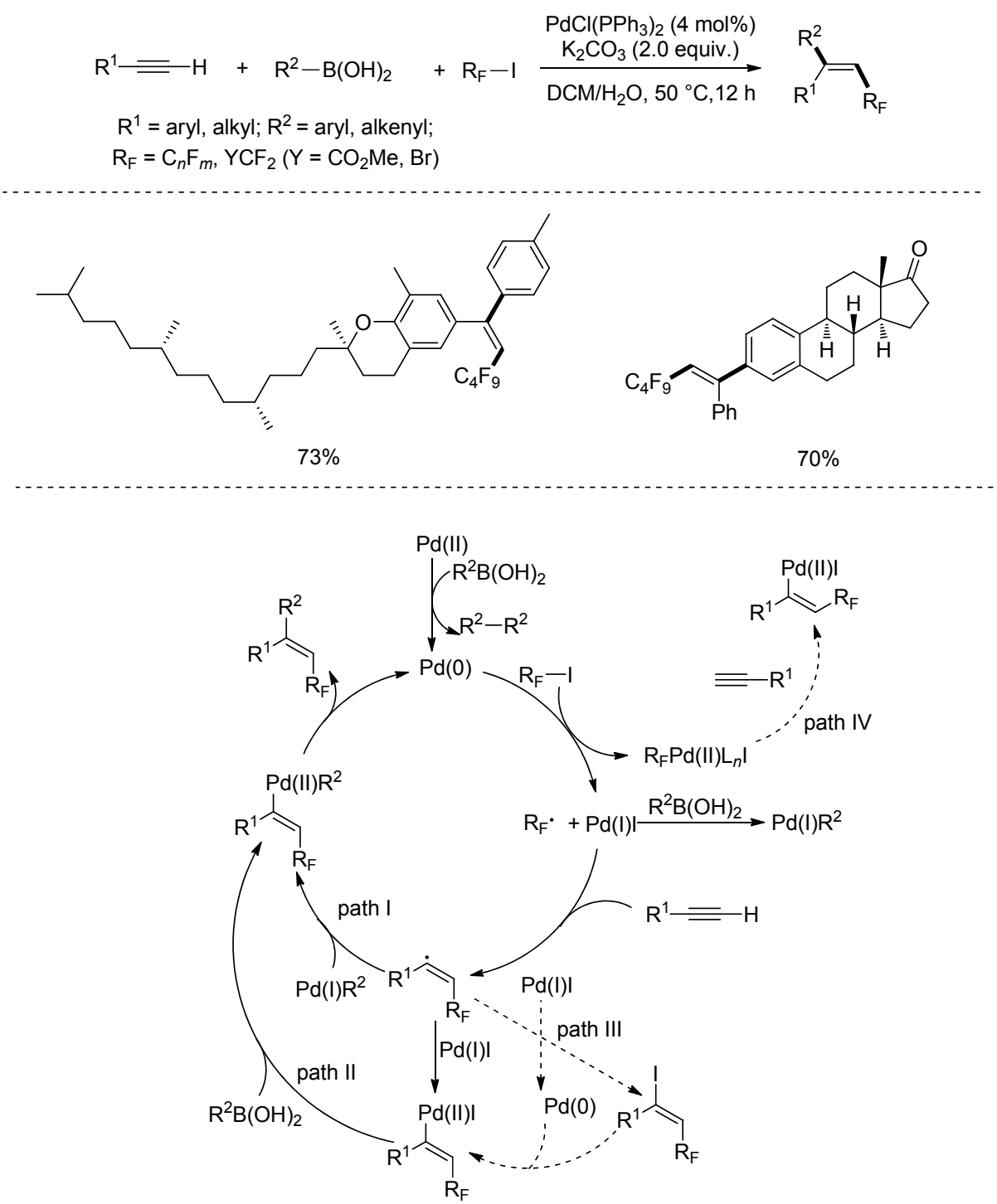

图式 10 钯催化下端炔、全氟碘代烷烃和硼酸三组分反应

Scheme 10 Palladium-catalyzed three-component reactions of terminal alkynes with iodoperfluoroalkanes and boronic acids

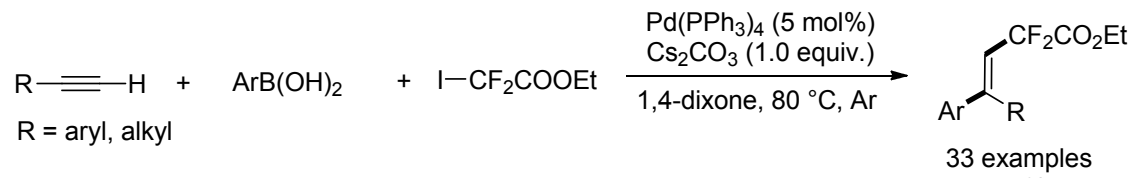
up to $89 \%$ yield<smiles>CCOC(=O)C(=O)OCC</smiles>

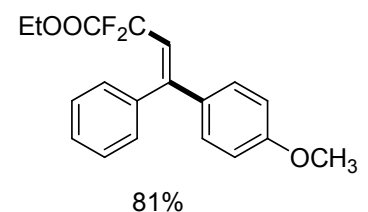<smiles>CCOC(F)(F)F</smiles>

$61 \%$<smiles>CCOC(=O)C(F)(F)C=C(c1ccccc1)c1ccc(C(=O)c2ccccc2)cc1</smiles>

$65 \%$ 


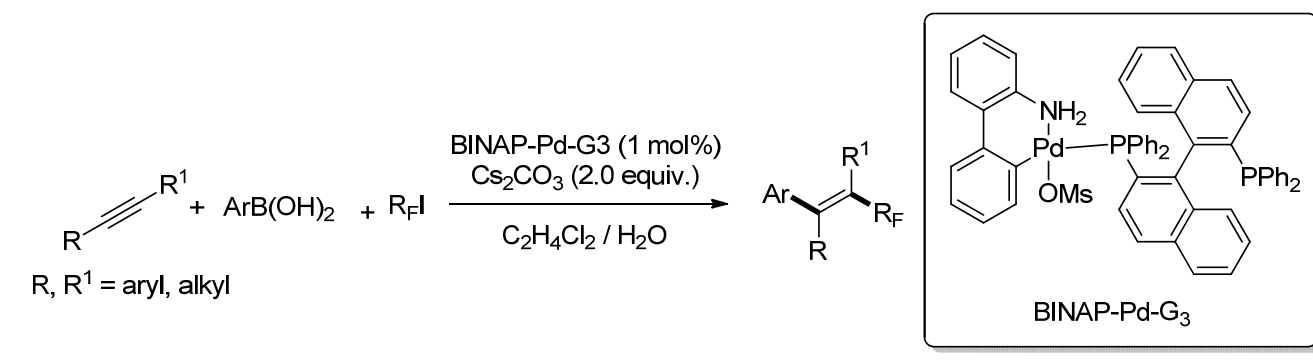

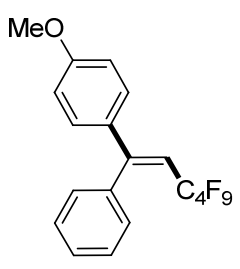

$86 \%$

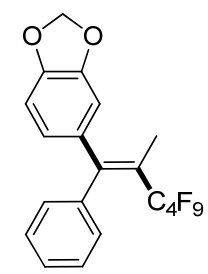

$92 \%$

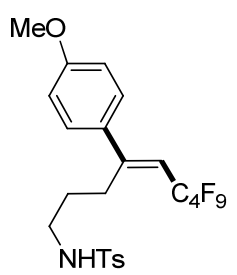

$82 \%$

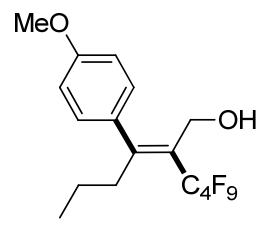

$57 \%, d r=5: 1$

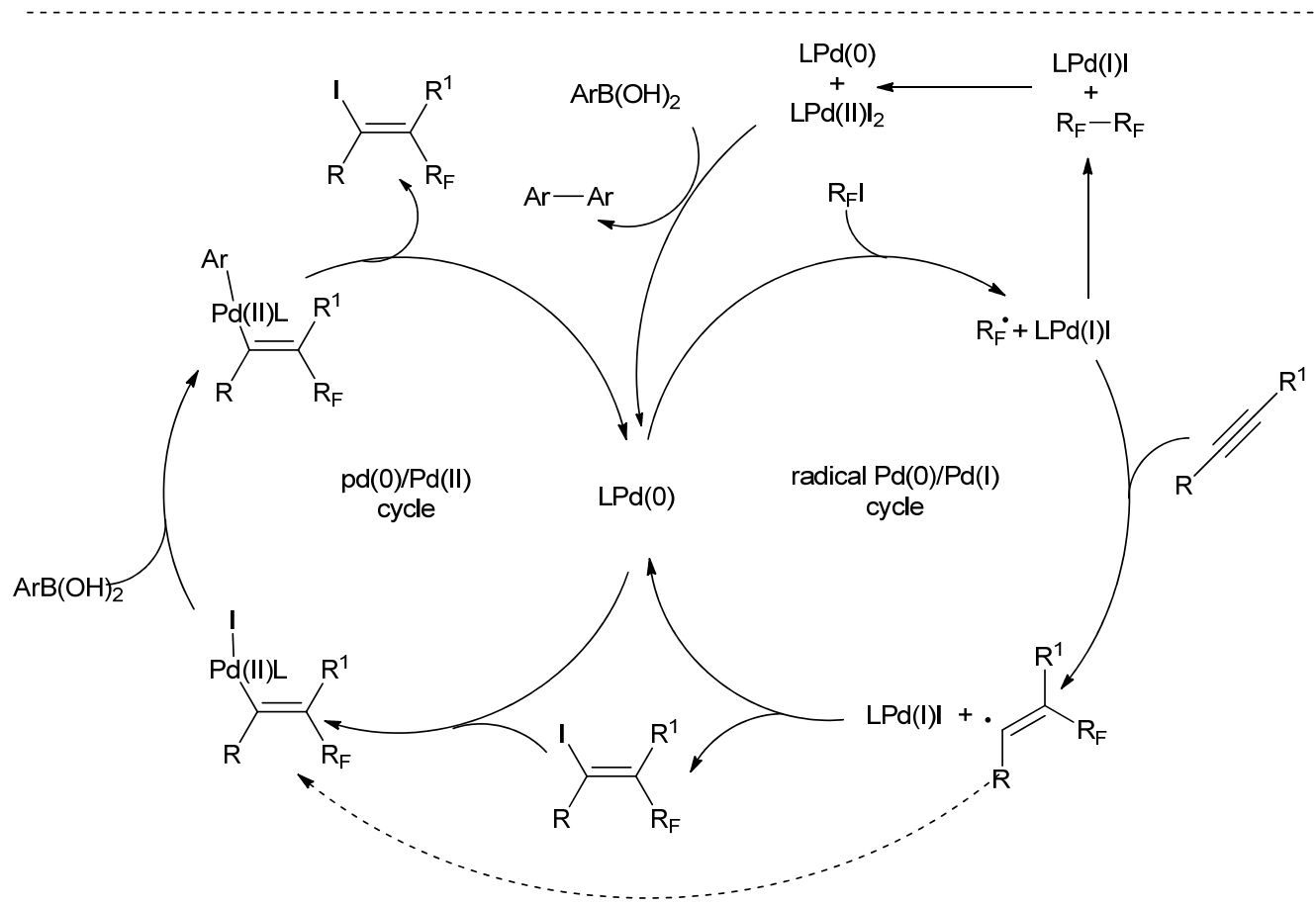

图式 11 钯催化下炔的全氟烷基化

Scheme 11 Palladium-catalyzed carboperfluoroalkylation of alkynes

\section{3 与芳烃的反应}

相对于烯烃和炔烃, 芳烃的自由基取代或者加成反 应由于可能涉及到去芳构化/芳构化的过程而显得极具 挑战性. 2013 年, 傅尧课题组 ${ }^{[2]}$ 实现了一系列非活化二 级溴代烷烃参与钯催化的吡啶氮氧化物邻位烷基化反 应(Scheme 12). 在最优条件下, 几乎所有底物均有较好 的收率, 并且可兼容多种官能团. 吡啶氮氧化衍生物表 现出很好的区域选择性, 只在邻位发生烷基化. 6-澳-1己烯和溴甲基环丁烷的自由基验证实验说明反应可能 经历了自由基历程. 尽管作者没有提出明确的反应机
理，但是在芳烃直接烷基化领域向前迈出了一大步.

Zhou 课题组 ${ }^{[27]}$ 发展了一种钯催化的杂芳烃与二、 三级卤代烃的区域选择性烷基化方法(Scheme 13). 在 $\mathrm{Pd}\left(\mathrm{PPh}_{3}\right)_{4}$ 为催化剂、 $\mathrm{dppp}$ 为配体、 $\mathrm{Cs}_{2} \mathrm{CO}_{3}$ 为碱的条件 下, 1,3-苯并噁唑、咪唑、吡咯、呋喃、噻吩等杂环化合 物可以实现与二级、三级碘代烷烃的烷基化反应. 添加 $\mathrm{NaI}$ 后，溴代烷烃在上述条件下也可以很好的反应，同 时在体系中检测到了少量的碘代烷烃, 说明参与反应的 可能是碘代烷烃. 值得一提的是，该体系不仅适用于一 级、二级烷基卤代物, 就连位阻更大的三级烷基卤代物 


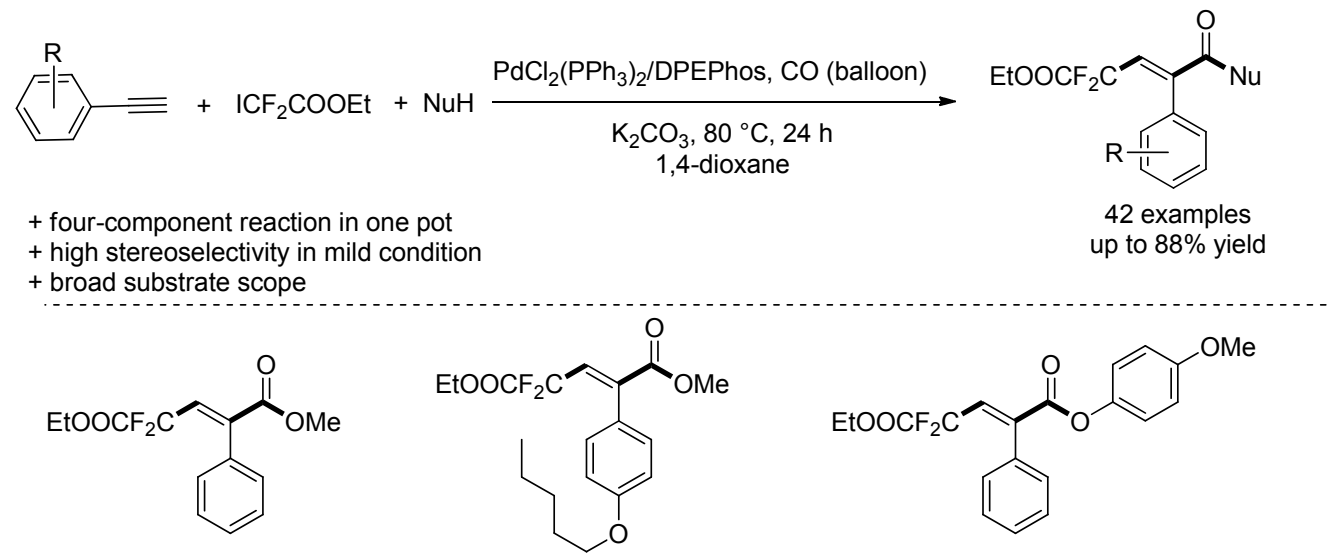

$88 \%, E / Z>20 / 1$

$81 \%, E / Z>20 / 1$

$53 \%, E / Z>20 / 1$<smiles>CCOC(=O)C=C(C(=O)Nc1ccc(C(C)(C)C)cc1)c1ccccc1</smiles>

$70 \%, E / Z>20 / 1$

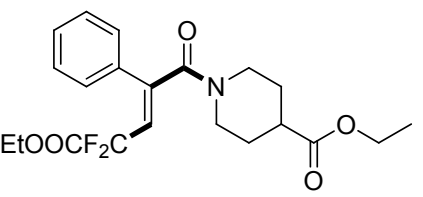

$59 \%$, only $E$

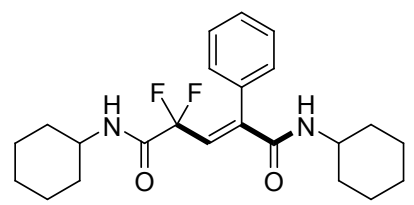

$59 \%, E / Z>20 / 1$

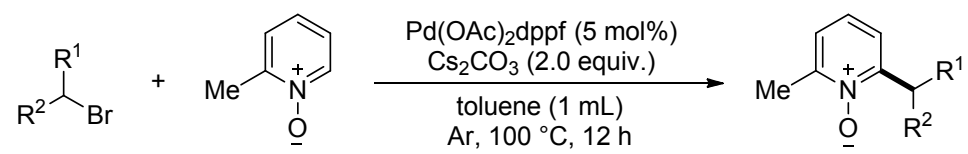

(1.0 equiv.) (2.0 equiv.)<smiles>Cc1cccc([C]2CCCCC2)[n+]1[O-]</smiles><smiles>Cc1cccc(C2CCOCC2)[n+]1[O-]</smiles><smiles>CC(C)=CCCC(C)c1cccc(C)[n+]1[O-]</smiles>

$88 \%$

$70 \%$<smiles>CCC(C)c1cccc(C)[n+]1[O-]</smiles>

$74 \%$<smiles>[O-][n+]1cccc2ccc3ccccc3c21</smiles>

$75 \%$
$44 \%$<smiles>[O-][n+]1c(Cl)cccc1-c1ccccn1</smiles>

$43 \%$<smiles>C=CCCCC[Br+]Br</smiles><smiles>C=CCCCc1cccc(C)[n+]1[O-]</smiles>

图式 12 钯催化的吡啶 $N$-氧化物与二级烷基溴的偶联

Scheme 12 Palladium-catalyzed $\mathrm{C}-\mathrm{H}$ activation/cross-coupling of pyridine $\mathrm{N}$-oxides with secondary alkyl bromides

也能参与转化. 综合理论计算与实验结果, 零价钯首先 与烷基卤代烃发生 SET 过程，生成 $\operatorname{Pd}(\mathrm{I})$ 和烷基自由基， 然后自由基与杂芳环发生自由基加成，随后芳基自由基 物种与 $[(\mathrm{dppp}) \mathrm{Pd}(\mathrm{I}) \mathrm{X}]$ 发生单电子转移, 再经去质子化
生成最终产物, 零价钯参与下一次的催化循环. 此外, 张扬会课题组 ${ }^{[28]}$ 在 2015 年也报道了类似的钯催化富电 子杂芳烃的二氟甲基化反应. 


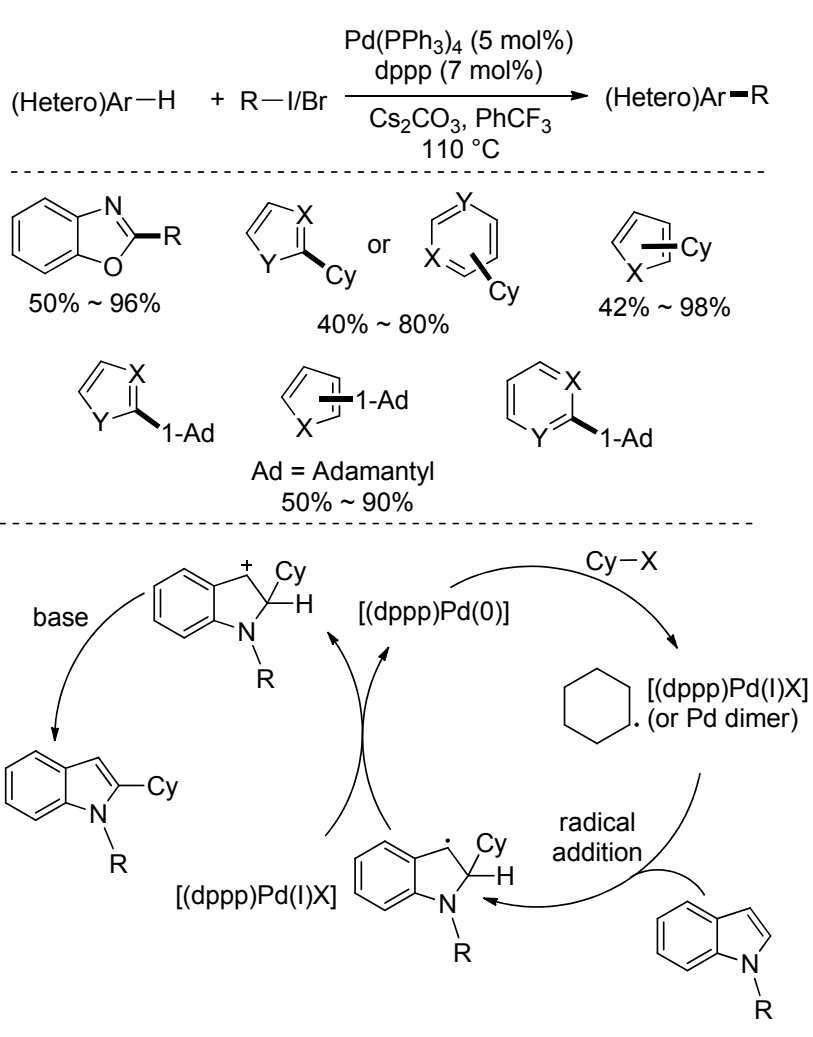

图式 13 杂芳烃与烷基卤代物的偶联

Scheme 13 Couplings of heteroarene and alkyl halides

Alexanian 课题组 ${ }^{[29]}$ 在 2015 年发展了一种钯催化非 活化烷基卤代烃与芳烃的分子内环化反应(Scheme 14). 以 $\mathrm{Pd}\left(\mathrm{PPh}_{3}\right)_{4}$ 为催化剂, $\mathrm{PMP}$ 为碱, 苯基叔丁烷为溶剂, $130{ }^{\circ} \mathrm{C}$ 反应 $48 \mathrm{~h}$ (以碘代烷烃为底物, 反应条件更为温 和), 高产率地得到一系列四氢蒜、二氢狮、氮取代的吲 哚啉、喹啉以及异喹啉等环化产物. 作者给出了可能的 反应机理, 零价钯与卤代烷烃先通过 SET 过程生成 $\mathrm{Pd}(\mathrm{I})$ 物种和碳自由基中间体，进而通过自由基加成得到 环己二烯自由基中间体, 再通过单电子氧化和去质子化 得最终产物. 邻位取代的芳基底物在生成产物后, 可能 会发生 1,2-烷基迁移生成环己二烯阳离子, 再芳构化形 成重排产物。

2016 年, 王官武课题组 ${ }^{[30]}$ 通过钉钯共催化和邻位 金属化的策略，实现了芳基间位的二氟甲基化(Eq. 7). 研究发现, 以 $\left[\mathrm{RuCl}_{2}(p \text {-cymene })\right]_{2}$ 和 $\mathrm{Pd}\left(\mathrm{PPh}_{3}\right)_{4}$ 作共催化 剂, $\mathrm{Na}_{2} \mathrm{CO}_{3}$ 作碱, $\mathrm{Ba}(\mathrm{OAc})_{2}$ 作添加剂, 以中高产率得到 一系列二氟甲基化、单氟甲基化或者非氟代甲基化产物. 本篇工作拓宽了近年来氟甲基化和钌催化的间位 $\mathrm{C}-\mathrm{H}$ 键活化的范围. 通过导向基团与钉催化剂形成环金属物 种, 从而增强了芳环间位的电子云密度, 进而与亲电性 的二氟甲基自由基反应(由二氟甲基化试剂与钯催化剂 通过单电子转移生成), 再经单电子氧化和去质子化等 步骤得到目标产物(Scheme 15).<smiles>[R]C([X])CCc1ccc[R1](C)c1</smiles>

$0.5 \mathrm{~mol} \cdot \mathrm{L}^{-1}$

- Alkyl bromides: 2.0 equiv. PMP, PhBu-t, $130^{\circ} \mathrm{C}$

- Alkyl iodides: 2.0 equiv. $\mathrm{K}_{3} \mathrm{PO}_{4}$, dioxane, $100{ }^{\circ} \mathrm{C}$

Al.

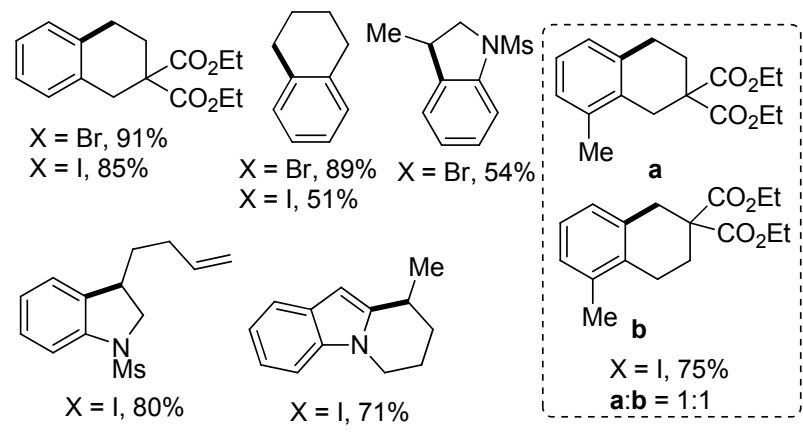

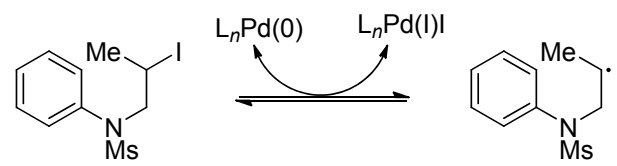

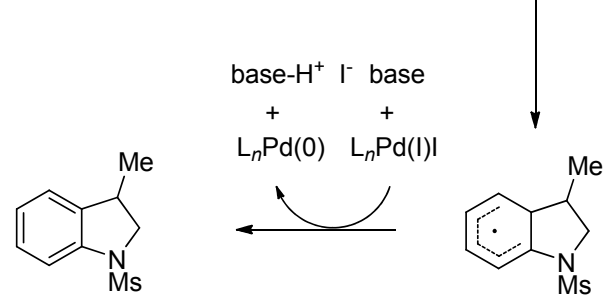

图式 14 非活化烷基卤代烃与芳烃的环化反应

Scheme 14 Synthesis of diverse cyclic heterocycles using the catalytic $\mathrm{C}-\mathrm{H}$ alkylation

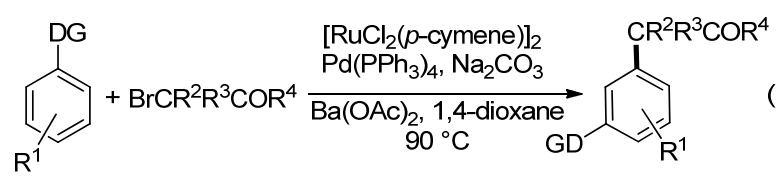

$\mathrm{DG}=$ pyridinyl, pyrimidinyl, pyrazolyl

$\mathrm{R}^{2}=\mathrm{F}, \mathrm{H} ; \mathrm{R}^{3}=\mathrm{F}, \mathrm{H} ; \mathrm{R}^{4}=\mathrm{OEt}$, amide

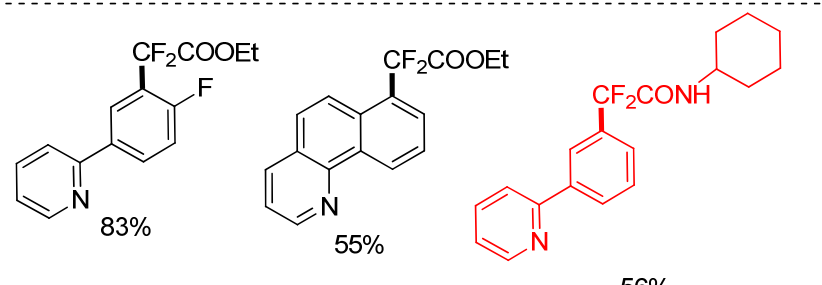

$56 \%$

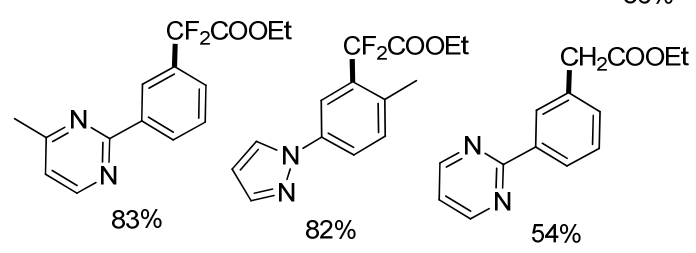




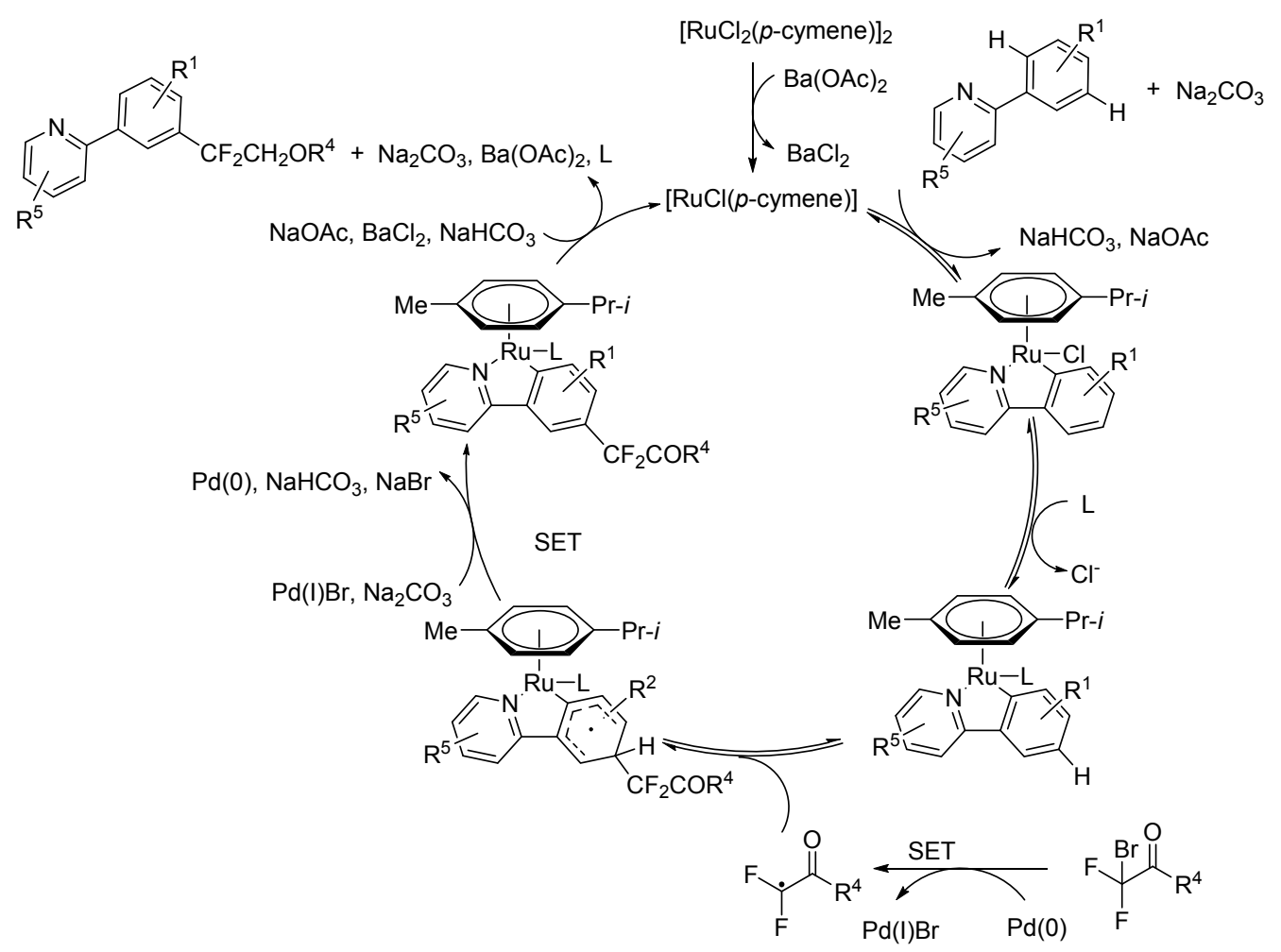

图式 15 钉钯共催化芳基二氟甲基化及其机理

Scheme 15 Pd and Ru co-catalyzed meta-difluoromethylation of arenes and plausible mechanism

\section{4 与 $\mathrm{CO}$ 的反应}

近年来出现了许多 $\mathrm{CO}$ 参与的自由基型反应, 同烷 基自由基与不饱和烃的反应类似, 烷基自由基同样来源 于烷基卤代物与 0 价钯的原子转移反应，同时产生 $\mathrm{Pd}(\mathrm{I})$ 物种, 启动自由基反应 ${ }^{[31]}$. 不同之处在于, 生成的烷基 自由基在 $\mathrm{CO}$ 的存在下优先与之加成生成较稳定的酰基 自由基, 酰基自由基物种随后被 $\operatorname{Pd}(\mathrm{I})$ 捕获发生后续反 应. 这种类型的反应被称为原子转移羰基化(ATC)反 应 $^{[2 \mathrm{~d}]}$. 活性自由基物种产生后, 其往往会与体系中的其 他活性物质发生复杂而精美的连锁反应, 因此这种类型 的反应又被称为多米诺反应 ${ }^{[2 \mathrm{e}]}$.

早在 1985 年, Tsuji 课题组 ${ }^{[32]}$ 就发展了一种钯催化 $\mathrm{CO}$ 参与的自由基型反应(Eq. 8). 反应在 $4.04 \mathrm{MPa} \mathrm{CO}$ 压力下, 使用 $\mathrm{EtOH}$ 为溶剂和反应物, 以 $\mathrm{Pd}(\mathrm{OAc})_{2}$ 为催 化剂, $\mathrm{PPh}_{3}$ 为配体, $\mathrm{K}_{2} \mathrm{CO}_{3}$ 为碱. 在这一反应中, $\mathrm{CCl}_{4}$ 或 $\mathrm{CCl}_{3} \mathrm{Br}$ 作为卤代烷烃, 与 0 价钯发生单电子转移反应, 生成烷基自由基, 随后与端位烯烃、 $\mathrm{CO}$ 反应, 再经醇解 生成相应的目标产物. 尽管烷基自由基与烯烃加成后直 接猝灭的产物与羰基化产物在体系中共存, 且反应时间 长, 底物范围窄, 但这一反应开创了原子转移羰基化反 应的先河.

随后, Fuchikami 课题组 ${ }^{[33]}$ 发展了全氟代烷基碘代 物的羰基化、双羰化反应(Eq. 9). 反应用胺类作为亲核

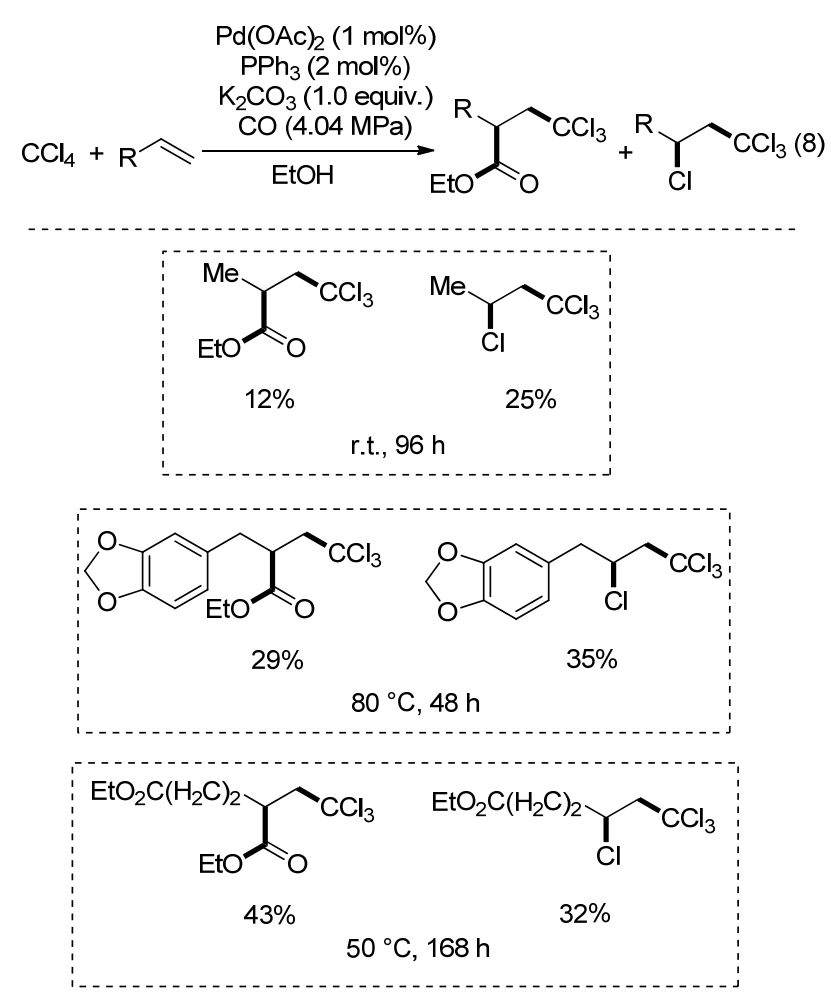

试剂, 使用 $5.05 \mathrm{MPa}$ 的 $\mathrm{CO}$, 在 $\mathrm{PdCl}_{2}\left(\mathrm{PPh}_{3}\right)_{2}$ 的催化下实 现. 该反应的产物可方便地转化为 $\alpha$-氨基酸. 然而, 反 应的选择性差依然是其一大缺陷. 
<smiles>[R]CC([R1])[NH2+]N[R]</smiles><smiles>[R]CC([R])C(=O)C(=O)N([R])[R]</smiles>

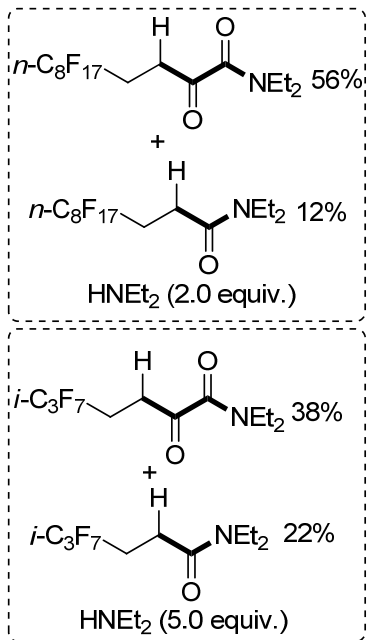

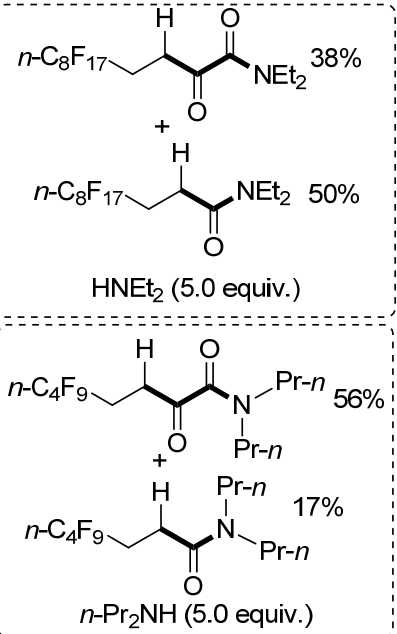

1991 年, Suzuki 及其合作者 ${ }^{[34]}$ 首次将钯催化原子转 移羰基化反应与 Suzuki 反应结合, 发展了一种新型的酮 类化合物合成方法(Eq. 10). 反应以 $\mathrm{Pd}\left(\mathrm{PPh}_{3}\right)_{4}$ 作为催化 剂, $\mathrm{K}_{3} \mathrm{PO}_{4}$ 为碱, 在 $101 \mathrm{kPa} \mathrm{CO}$ 以及光照下便可在室温 实现烷基碘代物、 $\mathrm{CO}$ 和 9-烷基-9-BBN 的温和偶联，具 有较好的官能团容忍性, 生物活性分子也可以得到兼 容.
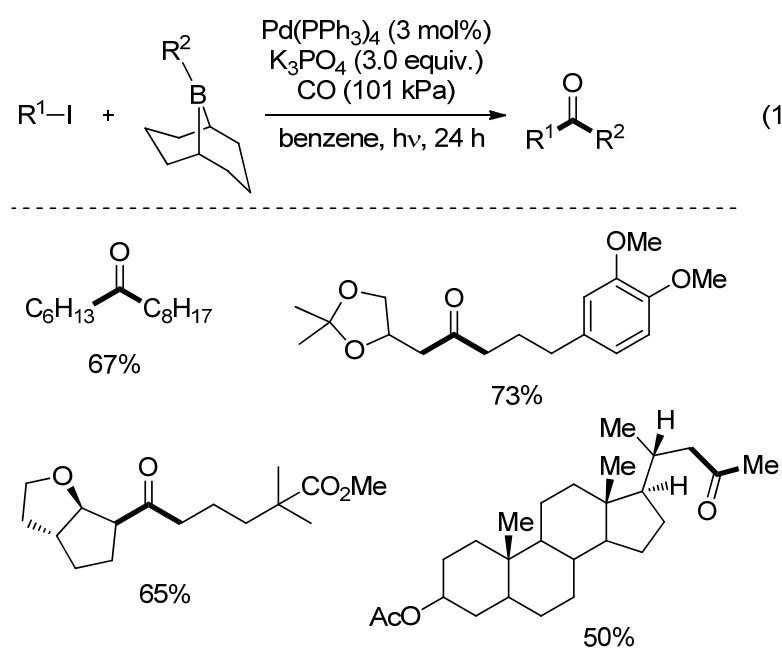

在此之后, Miyaura 等 ${ }^{[35]}$ 进一步发展了 Suzuki 的酮 类合成策略, 使用碘代烯烃与 $\mathrm{CO}$ 及 9-烷基-9-BBN 反 应，历经环化与羰基化过程生成酮类偶联产物(Eq. 11). 这种温和的反应条件同样造就了其良好的底物容忍性, 各类底物反应顺利，产物收率较高.

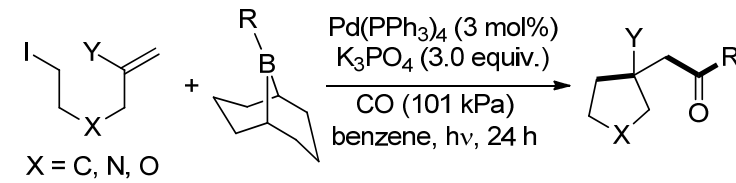$$
\mathrm{Y}=\mathrm{H}, \mathrm{Me}
$$

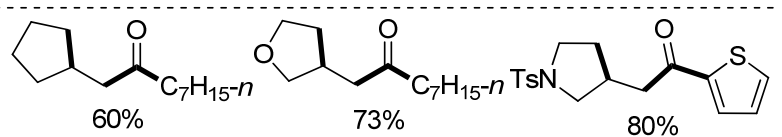

2002 年，原子转移羰基化反应这一概念被 Ryu 与 Komatsu 等 ${ }^{[36]}$ 所提出, 同时, 一种钯催化, 光促进的连 锁自由基多羰基化反应模式得到发展(Eq. 12). 反应使 用 $\mathrm{Pd}\left(\mathrm{PPh}_{3}\right)_{4}$ 作为催化剂, $\mathrm{Et}_{3} \mathrm{~N}$ 作为碱, 4-二甲氨基吡啶 (DMAP)作为添加剂, 在 $500 \mathrm{~W}$ 氙灯照射, $4.04 \mathrm{MPa} \mathrm{CO}$ 压力和 $8 \sim 40$ equiv. 醇类底物的存在下实现反应. 这一 钯一光催化体系在 15 个底物中实现了高达 $83 \%$ 的产率.

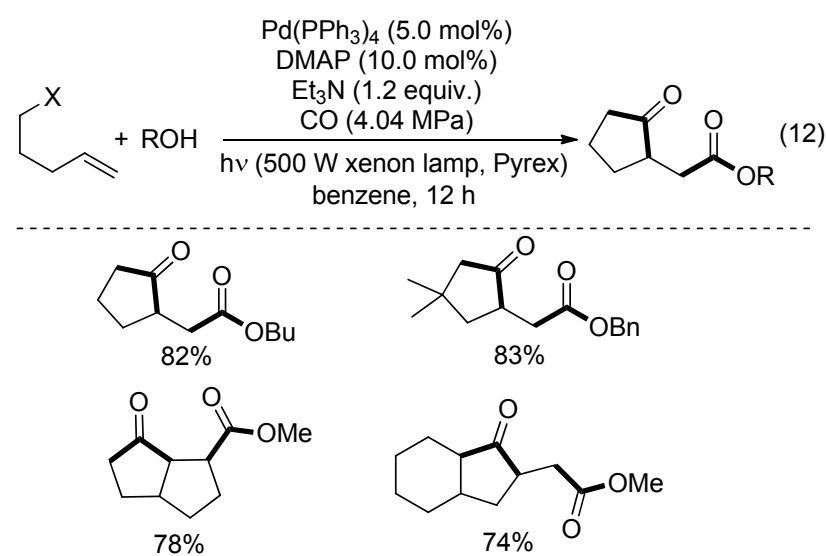

在这一反应中, 卤代物首先与 $\operatorname{Pd}(0)$ 发生原子转移, 生成烷基自由基和 $\mathrm{Pd}(\mathrm{I})$. 烷基自由基随后与 $\mathrm{CO}$ 反应并 发生 5-exo 分子内环化, 再一次捕获 $\mathrm{CO}$, 生成酰基自由 基. 这一酰基自由基与先前产生的 $\operatorname{Pd}(\mathrm{I})$ 物种结合，生成 酰基 $\mathrm{Pd}(\mathrm{II})$ 物种，在 $\mathrm{R}^{1} \mathrm{OH}$ 的存在下，还原消除生成最终 产物(Scheme 16).

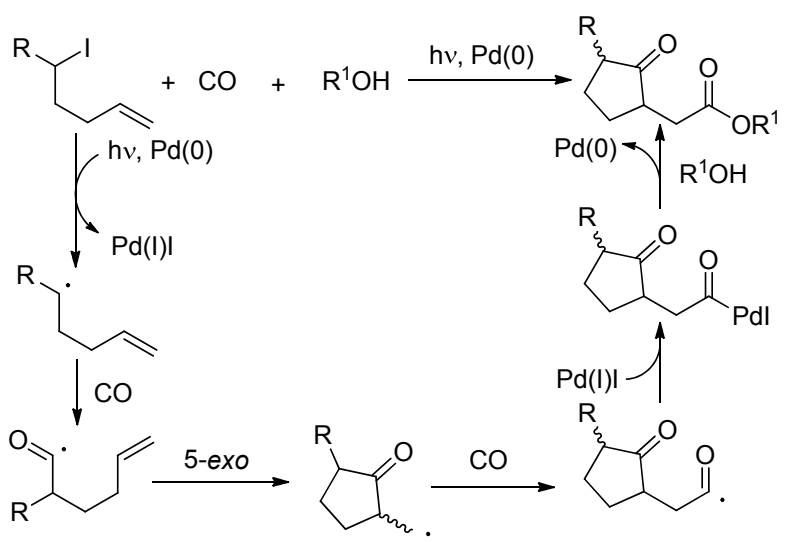

图式 16 钯-光催化羰基化机理

Scheme 16 Mechanism of Pd/photo-catalyzed carbonylation reactions 
在此之后, Ryu 课题组 ${ }^{[37]}$ 对光-钯催化体系的潜在 应用价值进行了深入挖掘. 2006 年, 不含烯基的烷基碘 代物的原子转移羰基化反应得以发展(Scheme 17). 在 这一反应中, 醇和胺都能以较好的产率生成最终产物.

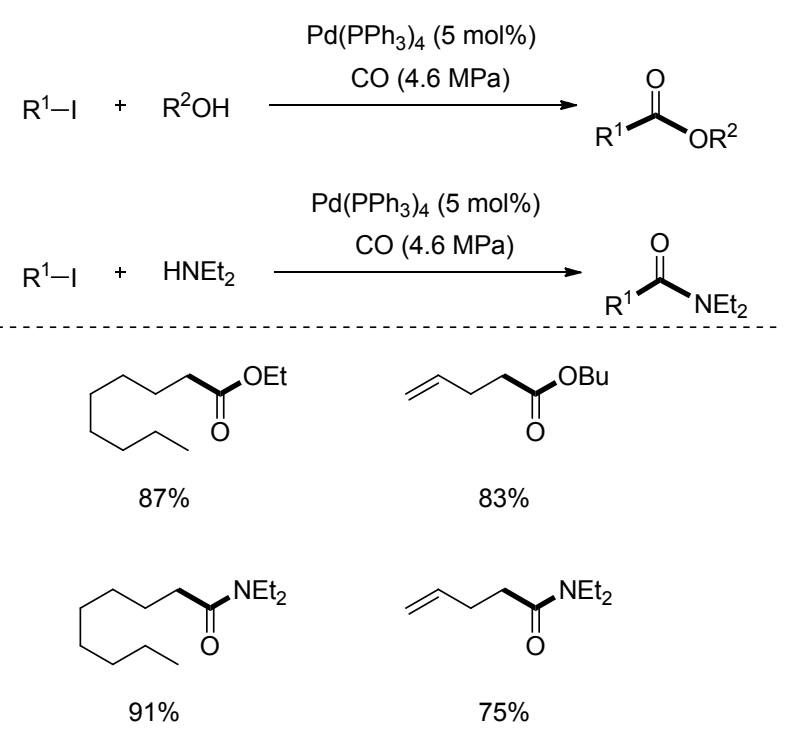

图式 17 碘代烷烃的钯-光催化羰基化反应

Scheme $17 \mathrm{Pd} /$ light catalyzed carbonylation reactions of iodoalkanes

2010 年, Alexanian 课题组 ${ }^{[38]}$ 发展了一种 Heck 反应 类型的钯催化羰基化反应(Eq. 13). 反应运用 $\mathrm{Pd}\left(\mathrm{PPh}_{3}\right)_{4}$ 作为催化剂, 2 equiv. $i$ - $\mathrm{Pr}_{2} \mathrm{NEt}$ 作为碱, 在 $5.07 \mathrm{MPa} \mathrm{CO}$ 压力、 $130{ }^{\circ} \mathrm{C}$ 实现. 在这一方法中, 一级和二级卤代物 都能顺利发生反应, 并生成应用广泛的烯酮产物. 通过 TEMPO 实验，涉及自由基的反应历程得到确认．

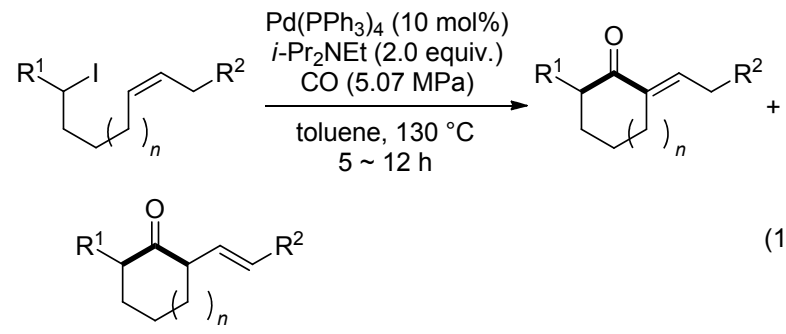

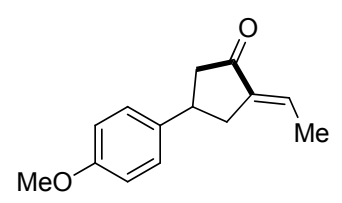

$77 \%, E / Z=10 / 1$

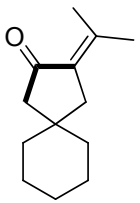

$90 \%$

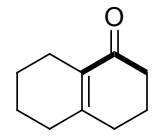

$69 \%$
与此同时, Ryu 课题组 ${ }^{[39]}$ 将其钯-光催化体系进一 步发展(Eq. 14), 使之能与端炔反应生成生物活性物质 中间体烷基炔基酮类化合物. 一级、二级和三级碘代烷 烃都能顺利完成反应.

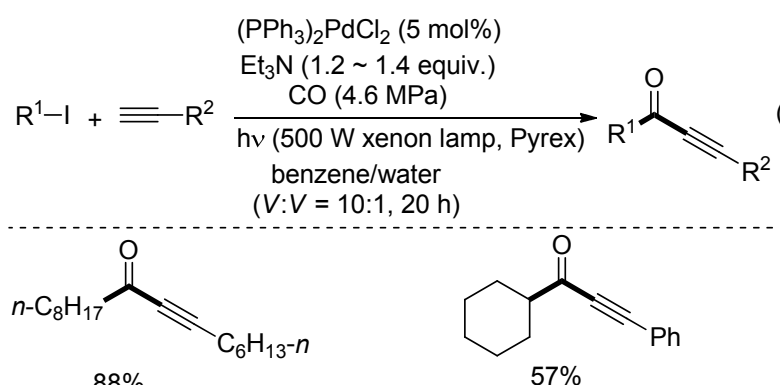

$88 \%$

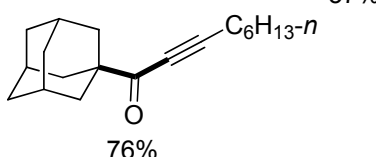

2011 年和 2012 年, Ryu 及其合作者 ${ }^{[40]}$ 实现并完善了 钯-光催化的四组分原子转移羰基化反应(Eq. 15), 通过 烷基碘代物、 $\mathrm{CO}$ 、烯烃和醇的共同反应生成酯. 当烯基 醇类物质作为反应物时，反应则为三组分反应，生成内 酯产物(a). 反应选择性好，满足多组分体系反应高效性 的基本要求. 此外, 除了常用的 $\left(\mathrm{PPh}_{3}\right)_{2} \mathrm{PdCl}_{2}$ 催化剂以 外, 二聚体 $\left[\mathrm{Pd}_{2}(\mathrm{MeCN})_{6}\right]\left(\mathrm{PF}_{6}\right)_{2}$ 在多组分反应中展现了 优异的催化能力 ${ }^{[40 b]}$.
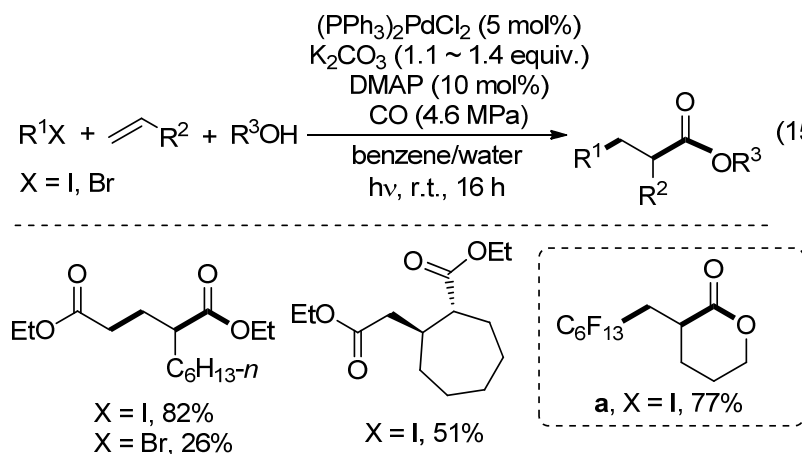

随后, 钯一光催化体系的应用被发挥到了极致 ${ }^{[41]}$. 在 2012 年到 2015 年中, Ryu 课题组先后实现了多种钯光催化在体系下的偶联反应. 2012 年, 碘代乙酸酯与

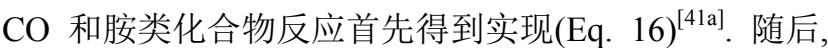
芳基硼酸的反应得到兼容，反应生成烷基芳基酮产物 (Eq. 17) ${ }^{[41 b]} .2015$ 年, Ryu 课题组再次证明其催化体系同 样适用于 Heck 类型的反应 (Eq. 18) ${ }^{[41 \mathrm{c}]}$ 以及 Suzuki 类型 的反应 $\left(\right.$ Eq. 19) ${ }^{[41 \mathrm{~d}]}$.
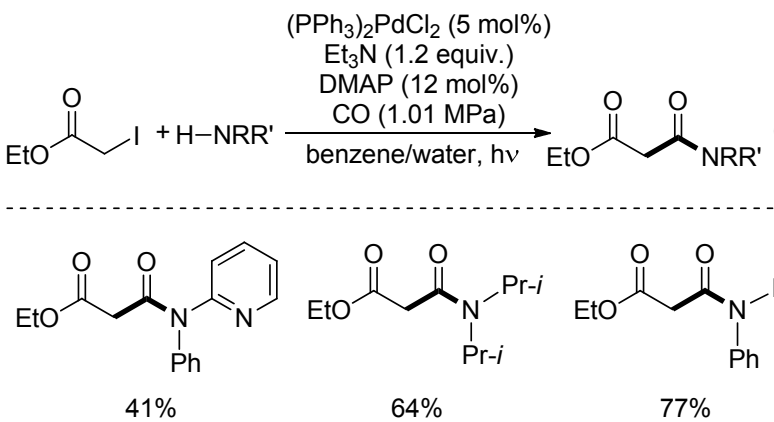<smiles>CCCN(P)C(=O)CC(=O)OCC</smiles><smiles>CCOC(=O)CC(=O)N(CC)c1ccccc1</smiles> 

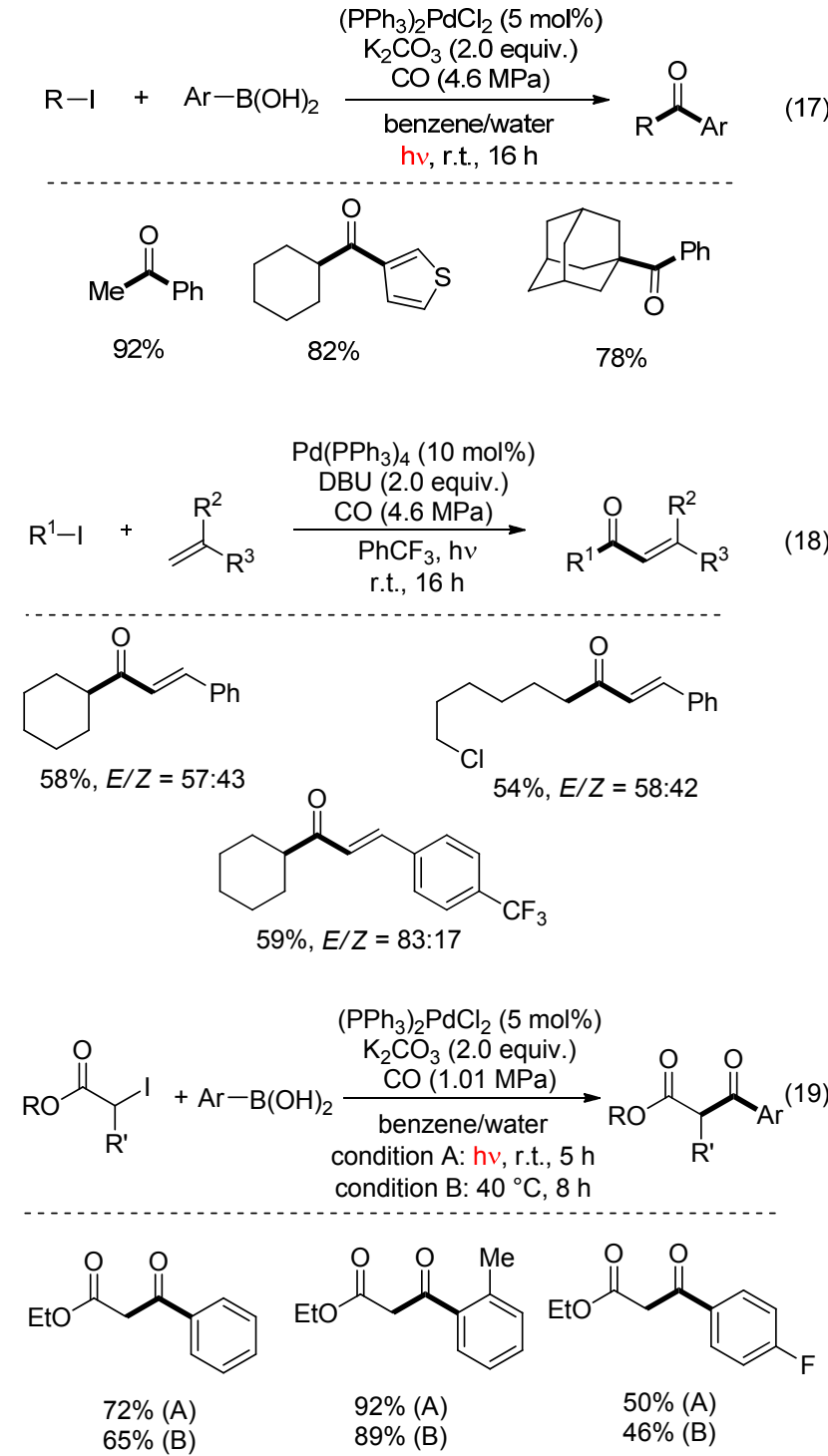

最近, 张新刚课题组 ${ }^{[42]}$ 发展了一种钯催化的二氟 甲基羰基化方法(Eq. 20). 反应使用 $1: 2$ 的芳基嗍酸和 $\mathrm{BrCF}_{2} \mathrm{CO}_{2} \mathrm{R}$ 或 $\mathrm{BrCF}_{2} \mathrm{CO}_{2} \mathrm{Et}$, 在 $\mathrm{PdCl}_{2}\left(\mathrm{PPh}_{3}\right)_{2}$, Xantphos,

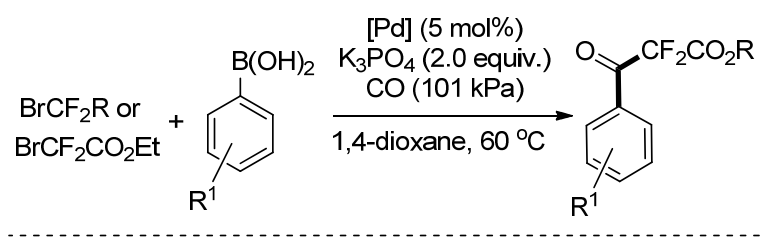<smiles>CCOC(=O)C(=O)C(=O)c1ccc(C(=O)C(F)(F)C(=O)OCC)cc1</smiles>

$\mathrm{Cu}(\mathrm{hfac})_{2}$ 共同催化下, 在二氧六环中反应 $24 \mathrm{~h}$ 实现. 此 方法将传统钯催化烷基卤代物的羰基化反应与新型二 氟甲基试剂结合起来，大大丰富了 $\mathrm{CO}$ 参与的羰基化反 应. 反应条件温和，仅使用 $101 \mathrm{kPa} \mathrm{CO}$ 进行反应.

同年, Alexanian 课题组 ${ }^{[43]}$ 实现了非活化的二级烷基 卤代物低压下的氧烷基羰基化反应(Eq. 21). 非活化的 二级烷基溴代物在强供电卡宾配位的钯的催化下实现 羰基化，并被作为混合溶剂的醇捕获生成酯类产物. 反 应有较好的产率和容忍性, 这一温和的转化方式同样兼 容生物活性物质.
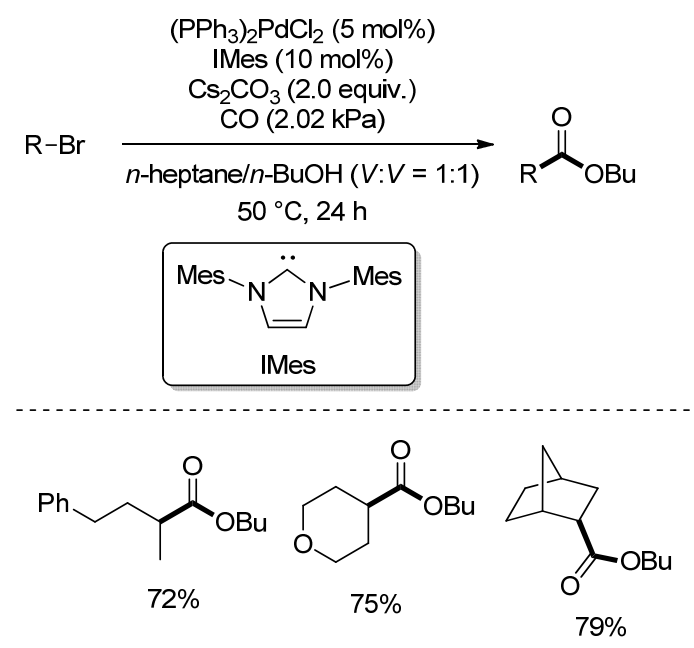

\section{5 其他反应}

\section{1 胺类 $\mathrm{C}-\mathrm{H}$ 键烷基化反应}

2016 年, Hartwig 课题组 ${ }^{[44]}$ 报道了利用三烷基膦 $\mathrm{Cy}_{2}(t-\mathrm{Bu}) \mathrm{P}$ (叔丁基二环已基膦)的位阻效应，实现钯催 化的非活化二级或三级卤代烃与二苯甲酮亚胺的偶联 反应(Eq. 22). 该反应以 $\left(\mathrm{Cy}_{2} t-\mathrm{BuP}\right)_{2} \mathrm{PdHBr}$ 为催化剂, $\mathrm{Cs}_{2} \mathrm{CO}_{3}$ 为碱, 叔戊醇为溶剂, $80{ }^{\circ} \mathrm{C}$ 反应 $24 \mathrm{~h}$, 高产率地 得到一系列偶联的产物. 实验结果说明, 反应可能含有 烷基自由基中间体. 作者认为, 溴代烷烃先与 $\operatorname{Pd}(0)$ 反 应生成烷基自由基和 $\operatorname{Pd}(\mathrm{I})$ 物种, 然后可能经历三种不 同的途径(Scheme 19). 其一, Pd(I)物种与亚胺进行配体 交换生成亚胺钯络合物, 紧接着亚胺钯络合物再与烷基 自由基形成 $\mathrm{C}-\mathrm{N}$ 键, 同时生成零价钯参与下一次的催 化循环(path I). 其二, 烷基自由基和 $\operatorname{Pd}(\mathrm{I})$ 物种进行自由 基加成, 生成的 $\operatorname{Pd}(\mathrm{II})$ 络合物在碱的作用下与亚胺发生 配体交换，最后通过还原消除构建 $\mathrm{C}-\mathrm{N}$ 键(path II). 其 三，通过烷基自由基与亚胺进行自由基加成形成 $\mathrm{C}-\mathrm{N}$ 键, 同时形成的碳自由基与 $\operatorname{Pd}(\mathrm{I})$ 物种加成生成 $\operatorname{Pd}(\mathrm{II})$ 配 合物，进而通过还原消除得到最终产物，同时产生的 $\mathrm{Pd}(\mathrm{II})$ 物种与碱作用生成零价钯参与下次催化循环(path III). 


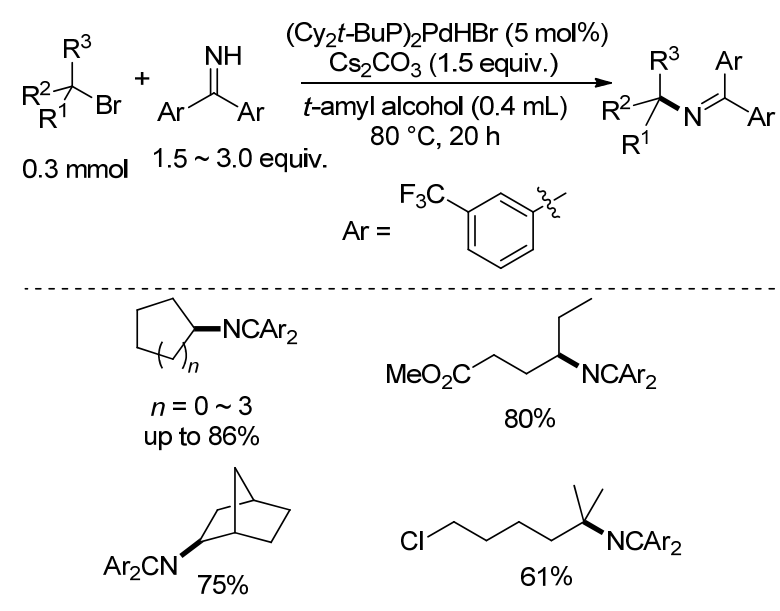

\section{2 腙 $\mathrm{C}-\mathrm{H}$ 键烷基化反应}

考虑含氟分子的独特性质, Bouyssi 和 Monteiro 课 题组 ${ }^{[45]}$ 在 2015 年报道了醛腙与溴代二氟乙酸乙酯的偶 联反应(Eq. 23). 该反应用 KOAc 作碱, $\left[\mathrm{Pd}_{2}(\mathrm{dba})_{3}\right]$ 作催 化剂, $t$-BuXantphos 作配体, 得到了一系列 $\mathrm{C}-\mathrm{C}$ 偶联产 物. 该反应底物适应性广泛, 各类芳香醛腙、吡啶醛腙、 喹啉醛腙、吡唑醛腙等均能很好的参与到反应之中. 硝 基、㲵基、酯基、醛基和卤素等官能团也可以兼容. 自 由基验证实验表明，该反应经历了自由基历程. 作者提 出的反应历程与上述 Hartwig 课题组二级或三级卤代烃 与二芳基甲酮亚胺的偶联反应机理类似(Scheme 19).

\section{6 总结与展望}

综上所述，金属钯构建的催化体系在卤代烷烃参与 的自由基型化学转化之中起到了举足轻重的作用. 随着 反应体系的不断完善, 越来越多的卤代烷烃被成功用于 该类转化之中, 也为该类反应的发展提供了许多新的机 遇，但是从目前来看，该类反应目前依然存在一些问题:
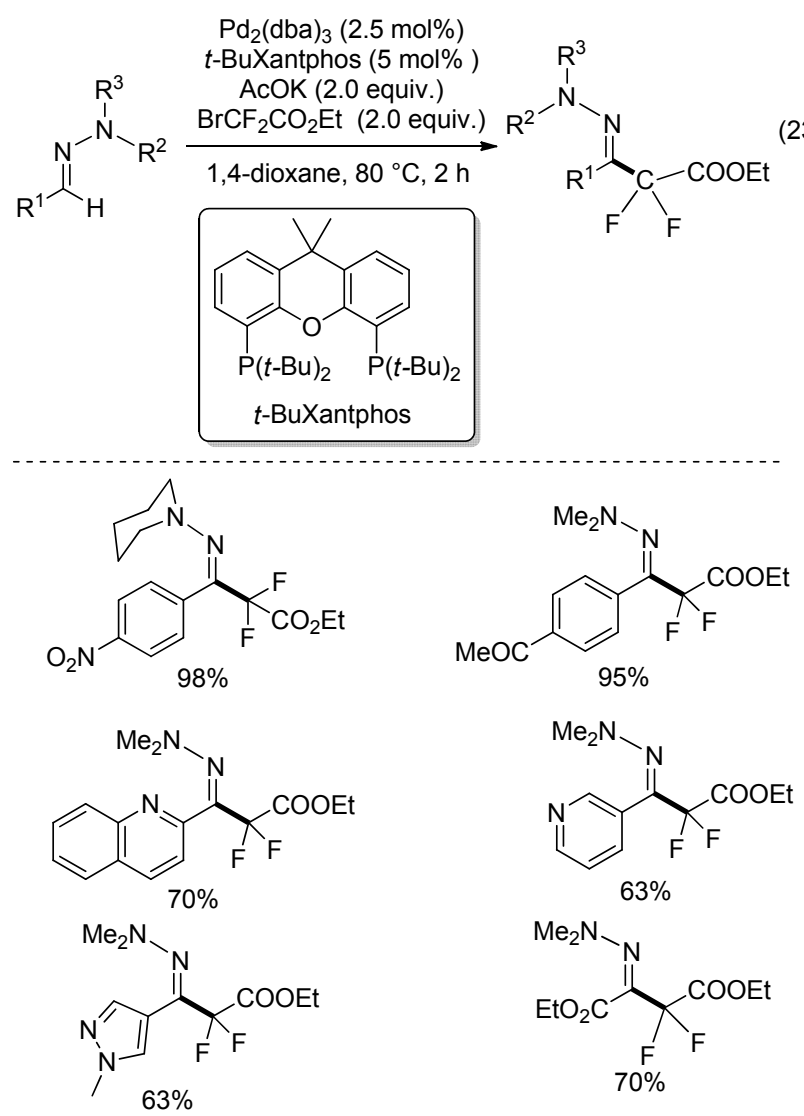

(1)成键类型较集中, 目前较多的工作集中在 $\mathrm{C}\left(\mathrm{sp}^{3}\right)$ $\mathrm{C}\left(\mathrm{sp}^{2}\right), \mathrm{C}\left(\mathrm{sp}^{3}\right)-\mathrm{C}(\mathrm{sp})$ 键的构建, 有关 $\mathrm{C}\left(\mathrm{sp}^{3}\right)-\mathrm{C}\left(\mathrm{sp}^{3}\right)$ 键构 建的报道较少; (2)反应类型较少，仅局限于与烯烃、炔 烃、一氧化碳等活性较高的物种反应，反应类型有待完 善. 烷基 $\mathrm{C}-\mathrm{H}$ 键作为最广泛存在的亲核试剂, 然而截 至目前，并没有出现该领域的成功报道; (3)大多数反应 需要在大位阻富电子膦配体、氮杂卡宾配体的辅助下才 能完成，这些配体大都价格昂贵，合成路线繁琐.由此

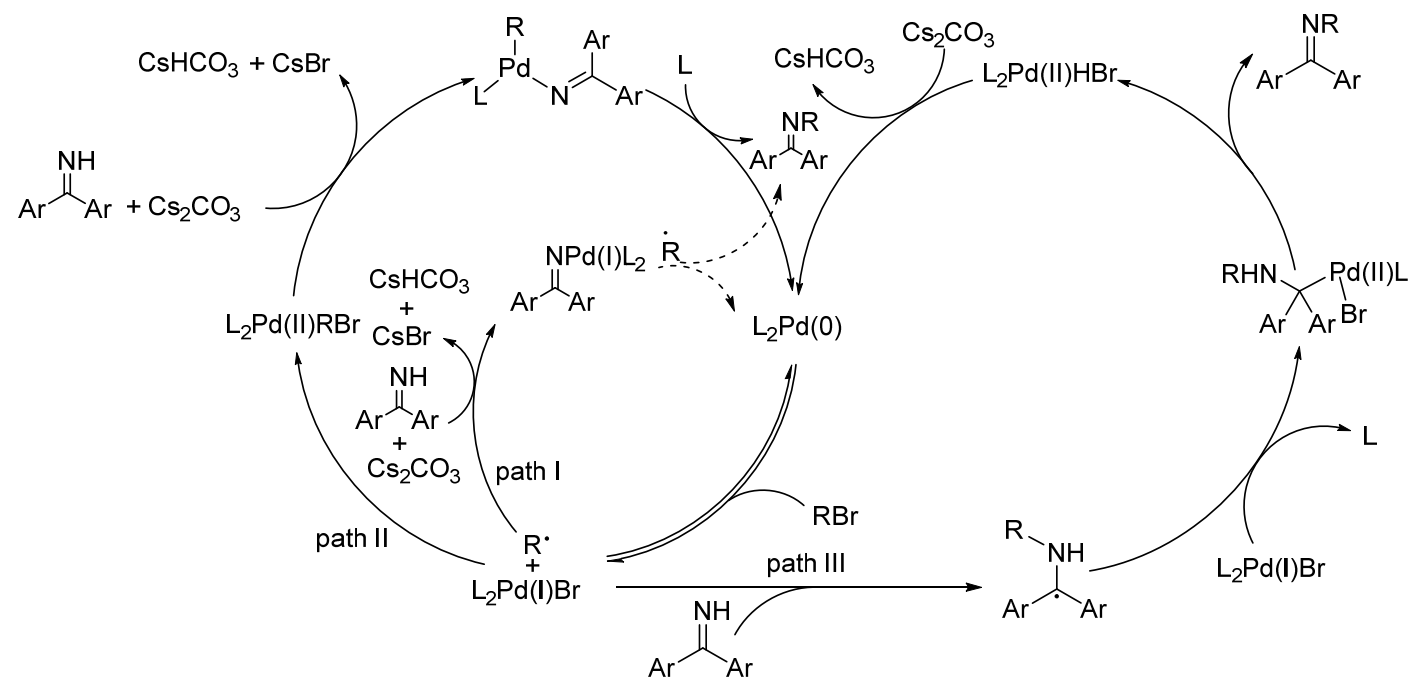

图式 19 亚胺 $N$-烷基化机理

Scheme 19 Plausible mechanisms for palladium-catalyzed $N$-alkylation of imines 
可见，在发展传统催化体系实现卤代烷烃自由基转化的 同时，探寻更加简单、高效、高选择性的催化体系，如 通过引入光、电等其他形式能量, 以实现反应类型更加 丰富、产品结构更加多样性的化学转化仍然是一个具有 挑战性和发展潜力的方向.

\section{Referenes}

[1] (a) Kochi, J. K.; Tamura, M. J. Am. Chem. Soc. 1971, 93, 1483. (b) Tamura, M.; Kochi, J. K. J. Organomet. Chem. 1972, 42, 205. (c) Ishiyama, T.; Abe, S.; Miyaura, N.; Suzuki, A. Chem. Lett. 1992, 21, 691 .

(d) Devasagayaraj, A.; Stüdemann, T.; Knochel, P. Angew. Chem., Int. Ed. 1996, 34, 2723.

[2] (a) Ryu, I. Chem. Soc. Rev. 2001, 30, 16.

(b) Frisch, A. C.; Beller, M. Angew. Chem., Int. Ed. 2005, 44, 674.

(c) Ackermann, L. Chem. Commun. 2010, 46, 4866.

(d) Sumino, S.; Fusano, A.; Fukuyama, T.; Ryu, I. Acc. Chem. Res. 2014, 47, 1563.

(e) Sebren, L. J.; Devery, J. J.; Stephenson, C. R. J. ACS Catal. 2014, 4, 703 .

(f) Zhang, W.; Dai, J.; Xu, H. Chin. J. Org. Chem. 2015, 35, 1820 (in Chinese).

(张文曼，戴建军，许华建，有机化学, 2015, 35, 1820.)

[3] Kambe, N.; Iwasaki, T.; Terao, J. Chem. Soc. Rev. 2011, 40, 4937.

[4] Ishihara, T.; Kuroboshi, M.; Okada, Y. Chem. Lett. 1986, 15, 1895.

[5] Curran, D. P.; Chang, C.-T. Tetrahedron Lett. 1990, 31, 933.

[6] Yi, P.; Zhang, Z.; Hu, H. Synth. Commun. 1992, 22, 2019.

[7] Surapanich, N.; Kuhakarn, C.; Pohmakotr, M.; Reutrakul, V. Eur. J. Org. Chem. 2012, 2012, 5943.

[8] Zou, Y.; Zhou, J. Chem. Commun. 2014, 50, 3725.

[9] Bissember, A. C.; Levina, A.; Fu, G. C. J. Am. Chem. Soc. 2012, 134, 14232.

[10] McMahon, C. M.; Alexanian, E. J. Angew. Chem., Int. Ed. 2014, 53, 5974.

[11] Bloome, K. S.; McMahen, R. L.; Alexanian, E. J. J. Am. Chem. Soc. 2011, 133, 20146.

[12] (a) Hidai, M.; Kokura, M.; Uchida, Y. J. Organomet. Chem. 1973, 52,431 .

(b) Ozawa, F.; Sugimoto, T.; Yuasa, Y.; Santra, M.; Yamamoto, T.; Yamamoto, A. Organometallics 1984, 3, 683.

(c) Cavinato, G.; Toniolo, L.; Vavasori, A. J. Mol. Catal. A: Chem. 2004, 219, 233.

[13] Dong, X.; Han, Y.; Yan, F.; Liu, Q.; Wang, P.; Chen, K.; Li, Y.; Zhao, Z.; Dong, Y.; Liu, H. Org. Lett. 2016, 18, 3774.

[14] Sumino, S.; Ryu, I. Org. Lett. 2016, 18, 52.

[15] Liu, H.; Qiao, Z.; Jiang, X. Org. Biomol. Chem. 2012, 10, 7274.

[16] Fan, J.-H.; Wei, W.-T.; Zhou, M.-B.; Song, R.-J.; Li, J.-H. Angew. Chem., Int. Ed. 2014, 53, 6650.

[17] Liu, Q.; Chen, C.; Tong, X. Tetrahedron Lett. 2015, 56, 4483.

[18] Wang, H.; Guo, L.-N.; Duan, X.-H. J. Org. Chem. 2016, 81, 860.

[19] Xia, X.-F.; Zhu, S.-L.; Li, Y.; Wang, H. RSC Adv. 2016, 6, 51703.
[20] Fruchey, E. R.; Monks, B. M.; Patterson, A. M.; Cook, S. P. Org. Lett. 2013, 15, 4362 .

[21] Monks, B. M.; Cook, S. P. Angew. Chem., Int. Ed. 2013, 52, 14214.

[22] Li, Z.; García-Domínguez, A.; Nevado, C. J. Am. Chem. Soc. 2015, $137,11610$.

[23] He, Y.-T.; Wang, Q.; Li, L.-H.; Liu, X.-Y.; Xu, P.-F.; Liang, Y.-M. Org. Lett. 2015, 17, 5188.

[24] Domański, S.; Chaładaj, W. ACS Catal. 2016, 6, 3452.

[25] Wang, Q.; He, Y.-T.; Zhao, J.-H.; Qiu, Y.-F.; Zheng, L.; Hu, J.-Y.; Yang, Y.-C.; Liu, X.-Y.; Liang, Y.-M. Org. Lett. 2016, 18, 2664.

[26] Xiao, B.; Liu, Z.-J.; Liu, L.; Fu, Y. J. Am. Chem. Soc. 2013, 135, 616.

[27] Wu, X.; See, J. W. T.; Xu, K.; Hirao, H.; Roger, J.; Hierso, J.-C.; Zhou, J. Angew. Chem., Int. Ed. 2014, 53, 13573.

[28] Shao, C.; Shi, G.; Zhang, Y.; Pan, S.; Guan, X. Org. Lett. 2015, 17, 2652.

[29] Venning, A. R. O.; Bohan, P. T.; Alexanian, E. J. J. Am. Chem. Soc. 2015, 137, 3731.

[30] Li, Z.-Y.; Li, L.; Li, Q.-L.; Jing, K.; Xu, H.; Wang, G.-W. Chem. Eur. J. 2017, 23, 3285.

[31] Liu, Q.; Dong, X.; Li, J.; Xiao, J.; Dong, Y.; Liu, H. ACS Catal. 2015, 5, 6111 .

[32] Tsuji, J.; Sato, K.; Nagashima, H. Tetrahedron 1985, 41, 5003

[33] Urata, H.; Ishii, Y.; Fuchikami, T. Tetrahedron Lett. 1989, 30, 4407.

[34] Ishiyama, T.; Miyaura, N.; Suzuki, A. Tetrahedron Lett. 1991, 32, 6923.

[35] Ishiyama, T.; Murata, M.; Suzuki, A.; Miyaura, N. J. Chem. Soc., Chem. Commun. 1995, 295.

[36] Ryu, I.; Kreimerman, S.; Araki, F.; Nishitani, S.; Oderaotoshi, Y.; Minakata, S.; Komatsu, M. J. Am. Chem. Soc. 2002, 124, 3812.

[37] Fukuyama, T.; Nishitani, S.; Inouye, T.; Morimoto, K.; Ryu, I. Org. Lett. 2006, 8, 1383.

[38] Bloome, K. S.; Alexanian, E. J. J. Am. Chem. Soc. 2010, 132, 12823

[39] Fusano, A.; Fukuyama, T.; Nishitani, S.; Inouye, T.; Ryu, I. Org. Lett. 2010, 12, 2410.

[40] (a) Fusano, A.; Sumino, S.; Fukuyama, T.; Ryu, I. Org. Lett. 2011 13,2114 .

(b) Fusano, A.; Sumino, S.; Nishitani, S.; Inouye, T.; Morimoto, K.; Fukuyama, T.; Ryu, I. Chem. Eur. J. 2012, 18, 9415.

[41] (a) Sumino, S.; Fusano, A.; Fukuyama, T.; Ryu, I. Synlett 2012, 23, 1331 .

(b) Sumino, S.; Ui, T.; Ryu, I. Org. Lett. 2013, 15, 3142.

(c) Sumino, S.; Ui, T.; Hamada, Y.; Fukuyama, T.; Ryu, I. Org. Lett. 2015, 17, 4952.

(d) Sumino, S.; Ui, T.; Ryu, I. Org. Chem. Front. 2015, $2,1085$.

[42] Zhao, H.-Y.; Feng, Z.; Luo, Z.; Zhang, X. Angew. Chem., Int. Ed. 2016, 55, 10401.

[43] Sargent, B. T.; Alexanian, E. J. J. Am. Chem. Soc. 2016, 138, 7520.

[44] Peacock, D. M.; Roos, C. B.; Hartwig, J. F. ACS Cent. Sci. 2016, 2 , 647.

[45] Prieto, A.; Melot, R.; Bouyssi, D.; Monteiro, N. Angew. Chem., Int. Ed. 2016, 55, 1885. 